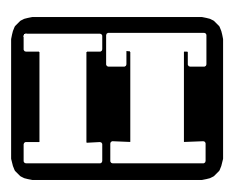

Summary of Micrographic Analysis of Selected Core Samples from Well ER-20-6\#1, in Support of Matrix Diffusion Testing

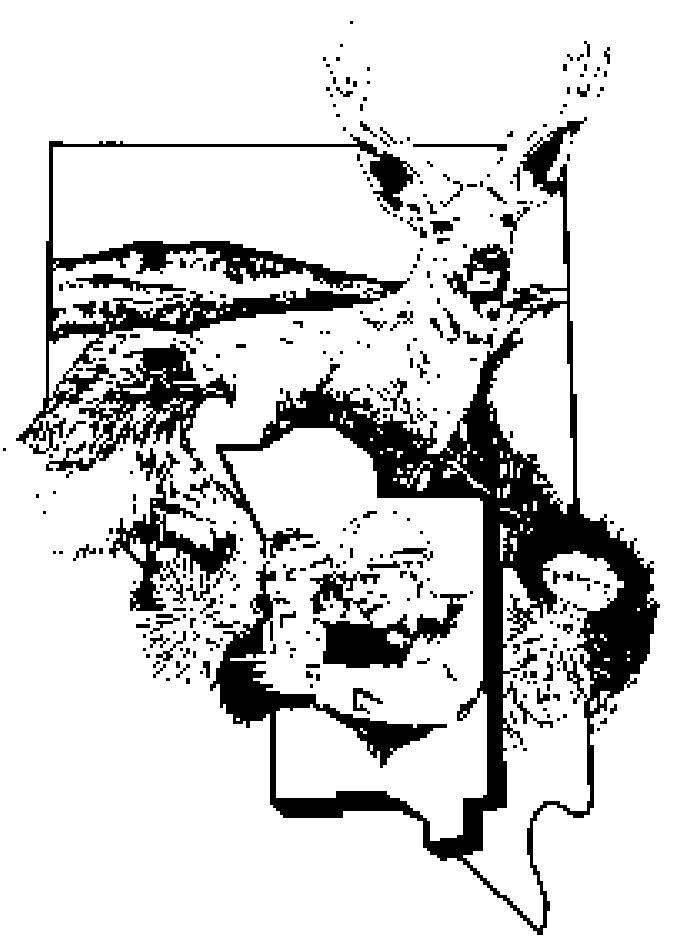

Revision No.: 0

September 1998 
Available to the public from -

U.S. Department of Commerce

National Technical I nformation Service

5285 Port Royal Road

Springfield, VA 22161

(703) $487-4650$

Available electronically at http://www.doe.gov/bridge. Available to U.S. Department of Energy and its contractors in paper from -

U.S. Department of Energy

Office of Scientific and Technical Information

P.O. Box 62

Oak Ridge, TN 37831-0062

(423) 576-8401 


\section{SUMMARY OF MICROGRAPHIC ANALYSIS OF SELECTED CORE SAMPLES FROM WELL ER-20-6\#1, IN SUPPORT OF MATRIX DIFFUSION TESTING}

Revision No.: 0

September 1998

IT CORPORATION

2621 Losee Road

Building B-1, Suite 3050-01

North Las Vegas, Nevada 89030 


\section{SUMMARY OF MICROGRAPHIC ANALYSIS OF SELECTED CORE SAMPLES FROM}

WELL ER-20-6\#1, IN SUPPORT OF MATRIX DIFFUSION TESTING

Approved by: $\frac{\text { Signature Approved }}{\text { J anet N. Wille, Project Manager }}$ Date: $\frac{9 / 25 / 98}{\text { IT Corporation }}$

Approved by: $\frac{\text { Signature Approved }}{\text { Mary Lou Brown, Program Manager }}$ Date: $\quad$ 9/25/98




\section{Table of Contents}

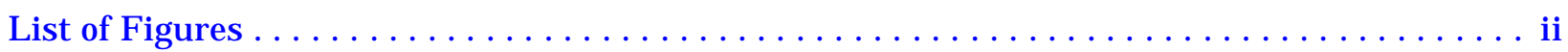

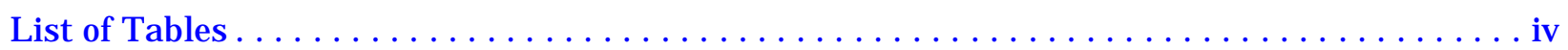

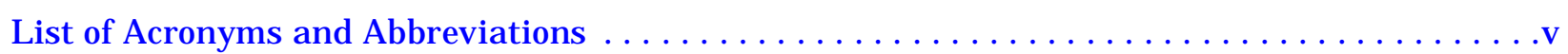

Conversion Factors $\ldots \ldots \ldots \ldots \ldots \ldots \ldots \ldots \ldots \ldots \ldots \ldots \ldots \ldots \ldots \ldots \ldots \ldots$

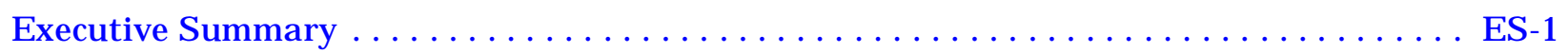

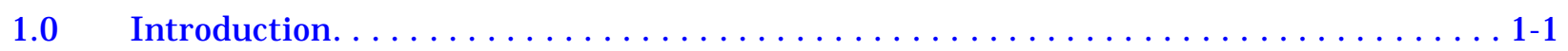

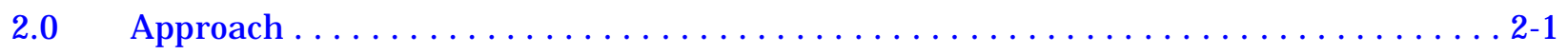

3.0 Sample Descriptions. . . . . . . . . . . . . . . .

$4.0 \quad$ Results. . . . . . . . . . . . . . . .

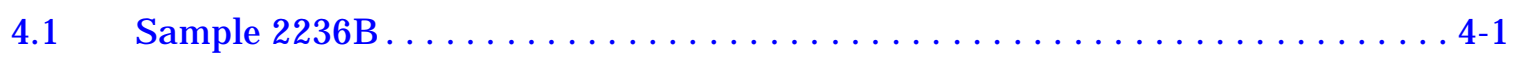

4.1.1 Optical Petrography.......................

4.1 .2 Scanning Electron Microscopy. . . . . . . . . . . . . . . . 4-2

4.1 .3 Electron Microprobe. . . . . . . . . . . . . . . . . . . 4-2

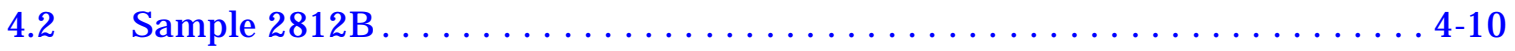

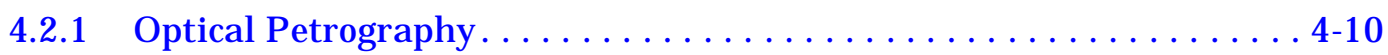

4.2 .2 Scanning Electron Microscopy. . . . . . . . . . . . . . . . . . 4-14

4.2 .3 Electron Microprobe. . . . . . . . . . . . . . . . . . . 4-14

4.3 Sample 2835B . . . . . . . . . . . . . . . . . . . . . . . . 4-20

4.3.1 Optical Petrography. . . . . . . . . . . . . . . . . . 4-26

4.3.2 Scanning Electron Microscopy. . . . . . . . . . . . . . . . 4-26

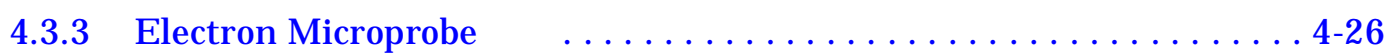

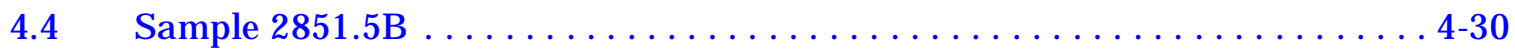

4.4.1 Optical Petrography....................... 4-30

4.4 .2 Scanning Electron Microscopy. . . . . . . . . . . . . . . . 4-31

4.4.3 Electron Microprobe. . . . . . . . . . . . . . . . . . . . . . . . 4-31

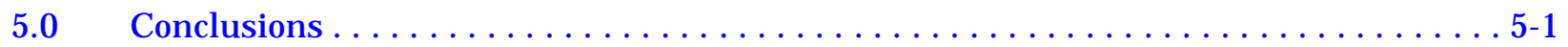

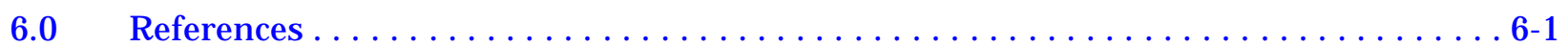


Number

4-1 Ribs in Clay "Mat" on F racture Surface $(2,236$ foot depth $) \ldots \ldots \ldots \ldots \ldots \ldots$ 4-3

4-2 Fracture Surface with Illite/Smectite Clay "Mat," Cracks Where Bridging Ribs in the Clay Mat have Pulled Away from Fracture Surface $(2,236$ foot depth) $\ldots \ldots \ldots \ldots \ldots \ldots \ldots \ldots, 4$

4-3 "Clean" F racture Cutting Illite/Smectite Clay “M at" (i/s), Opaline Silica (o), and Mordenite $(\mathrm{m})$ on Natural Fracture Surface $(2,236$ foot depth). . . . . . . . . . . . . . . . . . . .

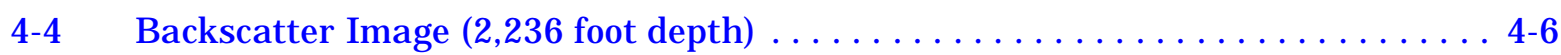

4-5 Elemental Map for Silica $(2,236$ foot depth) $\ldots \ldots \ldots \ldots \ldots \ldots \ldots \ldots \ldots .6$

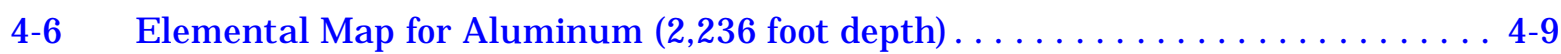

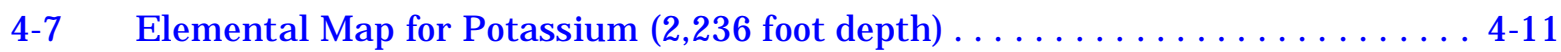

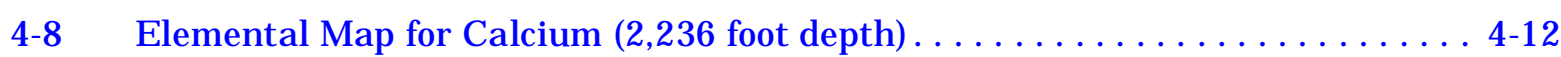

4-9 Elemental Map for Iron $(2,236$ foot depth) . . . . . . . . . . . . . . . . . . 4-13

4-10 Well Developed Flow Alignment in Quartz and Feldspar Crystals

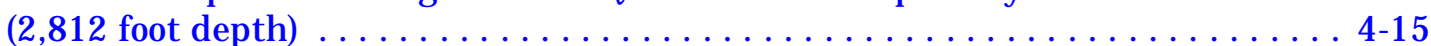

4-11 Illite/Smectite (i/s) Clay “M at" and Opaline Silica (o) (2,812 foot depth) . . . . . . 4-16

4-12 Illite After Feldspar $(2,812$ foot depth) . . . . . . . . . . . . . . . . . . . . . 4-17

4-13 Matrix Quartz (q), with Minor Illite (i) and Glass (g) (2,812 foot depth) . . . . . 4-18

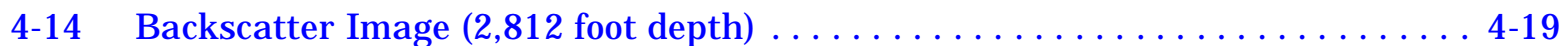

4-15 Elemental Map for Silica $(2,812$ foot depth) $\ldots \ldots \ldots \ldots \ldots \ldots \ldots \ldots \ldots$ 4-21

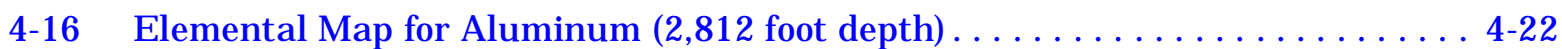

4-17 Elemental Map for Potassium $(2,812$ foot depth) $\ldots \ldots \ldots \ldots \ldots \ldots \ldots \ldots, 4 \ldots \ldots \ldots$

4-18 Elemental Map for Calcium (2,812 foot depth) . . . . . . . . . . . . . . . . . . . . 4-24

4-19 Elemental Map for Iron $(2,812$ foot depth) . . . . . . . . . . . . . . . . . 4-25

4-20 Elemental Map for Potassium (left) and Backscatter I mage (right)

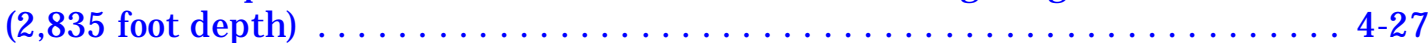

4-21 Elemental Map for Silica (left) and I ron (right) $(2,835$ foot depth) $\ldots \ldots \ldots \ldots$ 4-28

4-22 Elemental Map for Sodium (left) and Calcium (right) (2,835 foot depth) . . . . . 4-29

4-23 Overview of Fracture Surface $(2,851.5$ foot depth $) \ldots \ldots \ldots \ldots \ldots \ldots \ldots$ 4-32

4-24 Illite/Smectite Clay "Mat" Development on Fracture Surface $(2,851.5$ foot depth $) \ldots \ldots \ldots \ldots \ldots \ldots \ldots \ldots \ldots \ldots \ldots \ldots \ldots \ldots \ldots \ldots \ldots, 43$

4-25 Quartz (q), with Illite after Feldspar (i), and Mixed Illite/Smectite (i/s) Clay $(2,851.5$ foot depth). . . . . . . . . . . . . . . . . . . . . . . . . . 
Number

Title

Page

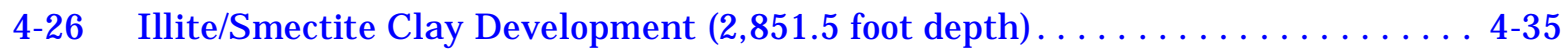

4-27 Backscatter Image $(2,851.5$ foot depth $) \ldots \ldots \ldots \ldots \ldots \ldots \ldots \ldots \ldots \ldots \ldots \ldots$. .36 $\ldots \ldots \ldots$

4-28 Elemental Map for Silica $(2,851.5$ foot depth). . . . . . . . . . . . . . . 4-37

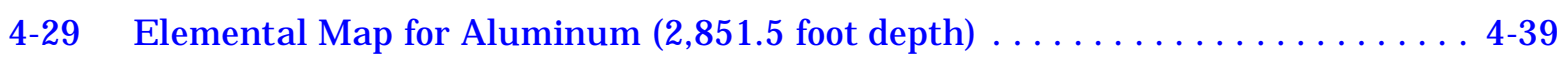

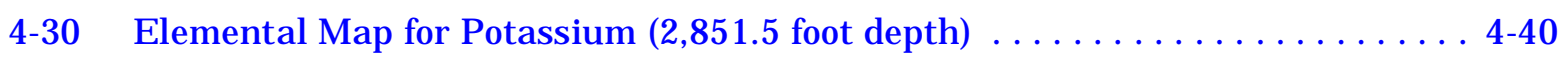

4-31 Elemental Map for Calcium $(2,851.5$ foot depth) $\ldots \ldots \ldots \ldots \ldots \ldots \ldots \ldots$.4 . . .

4-32 Elemental Map for Iron $(2,851.5$ foot depth) . . . . . . . . . . . . . . . . . . 4-42 


\section{List of Tables}

Number

Title

Page

4-1 Electron microprobe results (in weight percent oxide) for point analyses of specific phases in ER-20-6\#1 drill core samples . . 


\section{List of Acronyms and Abbreviations}

$\begin{array}{ll}\text { Al } & \text { Aluminum } \\ \mathrm{Ca} & \text { Calcium } \\ \mathrm{Fe} & \text { Iron } \\ \mathrm{K} & \text { Potassium } \\ \text { LANL } & \text { Los Alamos National Laboratory } \\ \mathrm{Mn} & \text { Manganese } \\ \mathrm{Na} & \text { Sodium } \\ \mathrm{SEM} & \text { Scanning electron microscope } \\ \mathrm{Si} & \text { Silicon } \\ \mathrm{Ti} & \text { Titanium }\end{array}$




\section{Conversion Factors}

Multiply

foot (ft)

inches (in.)

Micron

inch

inch $^{2}$
By

$3.048 \times 10^{-1}$

$2.54 \times 10^{0}$

$1 \times 10^{-6}$

$2.54 \times 10^{+1}$

$6.54 \times 10^{2}$

\section{To Obtain}

meter (m)

centimeter $(\mathrm{cm})$

meter (m)

millimeter

millimeter squared 


\section{Executive Summary}

Well ER-20-6\#1 was drilled in 1996 as part of a well cluster located to the southwest of the U-20bd emplacement hole in Area 20 on Pahute Mesa in the northwest corner of the Nevada Test Site. Being the closest well to the BULLION test cavity, ER-20-6\#1 was cored for later analysis to obtain information on the nature of fractures and lithology. The micrographic analysis of four core samples from drill hole ER-20-6\#1 indicates that the similarity in bulk chemical composition of the samples has resulted in very similar secondary mineral assemblages forming al ong natural fractures. Analyzed samples came from the 2,236 foot, 2,812 foot, 2,835 foot, and 2,851.5 foot depth intervals bel ow ground surface. All of the samples analyzed are part of the mafic-poor Calico Hills Formation and exhibit fracture-coating mineral assemblages dominated by mixed illite/smectite clay and illite after feldspar (in all four samples), with local opaline silica (at 2,236 and 2,812 foot depth), and a zeolite (tentatively identified as mordenite, at 2,236 foot depth). Based on a limited sample population, the degree to which these secondary phases have formed on fracture surfaces bears an apparently inverse relationship to the competency of the host lithology. This is reflected by variations in the degree of fracturing and the devel opment of secondary phases on fractures. In the flow breccia from 2,851.5 foot depth, thinly devel oped, localized coatings are devel oped al ong open aperture fractures in this competent rock type. Fractures in the devitrified lava from 2,812 foot depth are more irregular, and locally blocked by secondary mineral phases. Natural fractures in the zeolitized tuff from the 2,236 foot depth are discontinuous and irregular and typically obstructed with secondary mineral phases. There are also a second set of 'clean' fractures in the sample from 2,236 foot depth which lack any recognizable secondary mineral phases and are interpreted to be induced by proximity to the BULLION working point. Based on these results, it is expected that matrix diffusion will be enhanced in the samples $(2,236>2,812=2,835>2,851.5)$ where potentially transmissive fractures exhibit the greatest degree of obstruction. It is unknown what influence the induced fractures at 2,236 foot depth might have on diffusion given the lack of knowledge on their extent. It is assumed that the bulk matrix diffusion characteristics of the sample from 2,835 foot depth will be equivalent to the unfractured characteristics of the sample at 2,812 foot depth. 


\subsection{Introduction}

This report summarizes the activities conducted in support of matrix diffusion experiments being conducted by Los Alamos National Laboratory (LANL). These have been performed to provide a basis for the evaluation of fluid and solute movement, in the presence of potentially reactive solid phases, al ong or across fractures in rock and through the bulk rock matrix. 


\subsection{Approach}

Sample properties that were evaluated include:

- The general nature of porosity and microstructure devel opment; and

- Sample mineralogy, particularly secondary phases on fracture surfaces.

These sample evaluation activities were performed using optical petrographic, scanning el ectron micrographic, and electron microprobe techniques. The scanning el ectron mi croscope (SEM) and el ectron microprobe analyses were conducted with the assistance of Greg Meeker using the facilities, of the U.S. Geological Survey Microbeam Laboratory, at the Denver Federal Center in Lakewood, Colorado. The resultant data were evaluated in conjunction with other available information on cores from drill hole ER-20-6\#1. Two double-polished thin sections, without cover slips, were prepared for each fracture or feature of interest. This was done to provide one thin section for optical petrography and another thin section to be carbon-coated for use in the SEM and microprobe.

The scanning el ectron microscope used is a J EOL 5800L V coupled with an Oxford ISIS Energy Dispersion Spectroscopy (EDS) system. Typical accelerator voltage used on the SEM was 20 kilovolts. Due to the size constraints of the SEM sample chamber, portions (up to $3 \times 3 \mathrm{~cm}$ ) of the natural exposed open fracture surfaces were separated from the main sample and gold-coated for textural and mineralogical evaluation in the SEM.

The electron microprobe is a J E OL 8900. Microprobe analyses were conducted wavelength dispersive spectrometry using atomic number -absorption fluorescence (ZAF) oxide correction procedures.

Backscatter images and quantitative, large-scale digital $x$-ray images (or elemental maps) were collected using wavelength spectrometers (for $\mathrm{Al}, \mathrm{Ca}, \mathrm{Fe}, \mathrm{K}, \mathrm{Na}$, and $\mathrm{Si}$ ) by rastering the stage under a stationary electron probe. I mages were obtained from areas ranging from 4 to 200 millimeter $^{2}$ using array sizes ranging from 500 by 1000 to 1000 by 1000 pixels with pixel sizes ranging from 2 to 20 microns. 


\subsection{Sample Descriptions}

Four small sub-samples of cores collected by LANL from material archived at the U.S. Geological Survey Core Library in Mercury, NV were received by HSI GeoTrans on J une 15, 1998. These samples are representative of the material undergoing matrix diffusion testing at LANL.

Samples were received from cores collected at the following depths:

- 2,236 feet - approximately $4 \times 6 \times 5 \mathrm{~cm}$ sample labeled "2236B". One open fracture surface is represented on this sample;

- 2,812 feet - approximately 3×5×1.5 cm sample labeled "2812B". One open fracture surface is represented on this sample;

- 2,835 feet - approximately $2 \times 5 \times 1.5 \mathrm{~cm}$ sample labeled "2835B". One internal compositional segregation is present in this sample that is parallel to flow banding; and,

- 2,851.5 feet - approximately $6 \times 6 \times 5 \mathrm{~cm}$ sample label ed "2851.5B". Numerous irregular intersecting fractures are present in this sample. Fractures are represented by both open internal fractures and open fracture surfaces on the exterior of the sample. 


\subsection{Results}

The results for each of the samples include a general description by Prothro et al (1997). Analytical results from optical petrography, scanning electron microscopy, and electron microprobe are included.

\subsection{Sample 2236B}

Existing information (Prothro et al, 1997) has described this material as a zeolitic, non-welded tuff comprising the confining unit of the Calico Hills F ormation. The sample comes from a highly broken interval of core (2,214 to 2,243 feet) from the same approximate el evation as the working point of the BULLION test, located 544 feet to the northeast. It was uncertain in this description whether the fractures present in this interval are natural in origin. Fracture density is indicated to be 1 to 2 fractures per foot. Mineralogically, the sample has been described (Prothro et al, 1997) as containing rare to minor pumice, with rare phenocrysts of feldspar and quartz, rare biotite, and rare to minor lithic fragments. This particular sample has one exposed open fracture face which is the focus of this activity.

\subsubsection{Optical Petrography}

The tuff consists of sparse quartz (up to 0.25 millimeter) and feldspar (up to $0.20 \times 0.35$ millimeter) phenocrysts with pumice/lapilli fragments (up to $0.35 \times 0.45$ millimeter) in a devitrified matrix with abundant zeolite and opaque minerals. The matrix textural details have been largely obscured by the devitrification process.

Several styles of fracture development are evident in thin section. An open fracture face is transected by the thin section. There is a less-well developed fracture set that is sub-parallel to the exposed fracture surface. The sample is also cut by enclosed fractures that are essentially normal to the open fracture on the sample surface. A faint 'network' of thin ( $<0.05$ millimeter) inter secting linear zeolite accumulations may reflect a relict fracture set.

Petrographic examination of this sample indicates that the open fracture face is likely to be of natural origin. The fracture surface has a consistently devel oped secondary mineral selvage that is typically 0.01 to 0.03 millimeter in thickness and comprised of a very 
fine-grained ( $<0.002$ millimeter) mixed mineral assemblage with iron staining suggesting the presence of iron oxides. The sub-parallel fractures are filled with this iron-oxide stained mixture. The enclosed fractures are discontinuous along their length and irregular in orientation. The enclosed fractures have an aperture opening of approximately 0.05 to 0.1 millimeter and are also typically filled with the mixed mineral-iron-oxide assemblage of very fine grain size.

Numerous vesicles (typically 1 to 2 millimeter) are present in this sample. The vesicles are partially to completely filled with typically radiating zeolite (mordenite?).

\subsubsection{Scanning Electron Microscopy}

SEM evaluation shows the fracture surface to be largely coated with a clay 'mat' comprised predominantly of mixed smectite and illite clay minerals. As shown in Figure 4-1, this mat commonly has ribs reflecting a bridging of the fracture aperture, providing evidence that the fractures in this sample are largely filled and only partially available for the transmission of water. A close-up view (Figure 4-2) of the mat surface shows cracks and windows in the day mat which are assumed to have taken place upon separation of the matted fracture surfaces. Figure 4-3 shows a magnified view of a crack cutting an area of the sample where the clay mat is poorly developed or preserved. In this figure, well-developed delicate secondary phases (opaline silica indicated as ' $o$ ' in the image; illite/smectite - indicated as 'i/s'; and the zeolite identified as mordenite, based on morphology and cation content, - indicated as ' $m$ ') are offset by an apparently later fracture where secondary phase devel opment appears to be minimal. This style of 'clean' fracture may be a result of sample handling or, as suggested by Prothro et al (1997), may have been induced due to proximity to the BULLION working point. A 'point-count' analysis of the fracture surface indicate it to be 90 percent covered by the clay mat, 4 percent covered by mordenite, and 6 percent covered by opaline silica.

\subsubsection{Electron Microprobe}

Electron microprobe analysis of a thin section both transecting the exposed fracture surface and containing two open aperture fractures provided a backscatter image (Figure 4-4) revealing the textural and structural relationships within the field of view. This analysis also provided five elemental maps (one each for $\mathrm{Si}, \mathrm{Al}, \mathrm{K}, \mathrm{Ca}$, and $\mathrm{Fe}$; Figures 4-5, 4-6, 4-7, 4-8, and 4-9, respectively) for the same area contained in the backscatter image. Several quantitative point analyses of specific phases identified on the thin section were performed and are summarized in Table 4-1. 


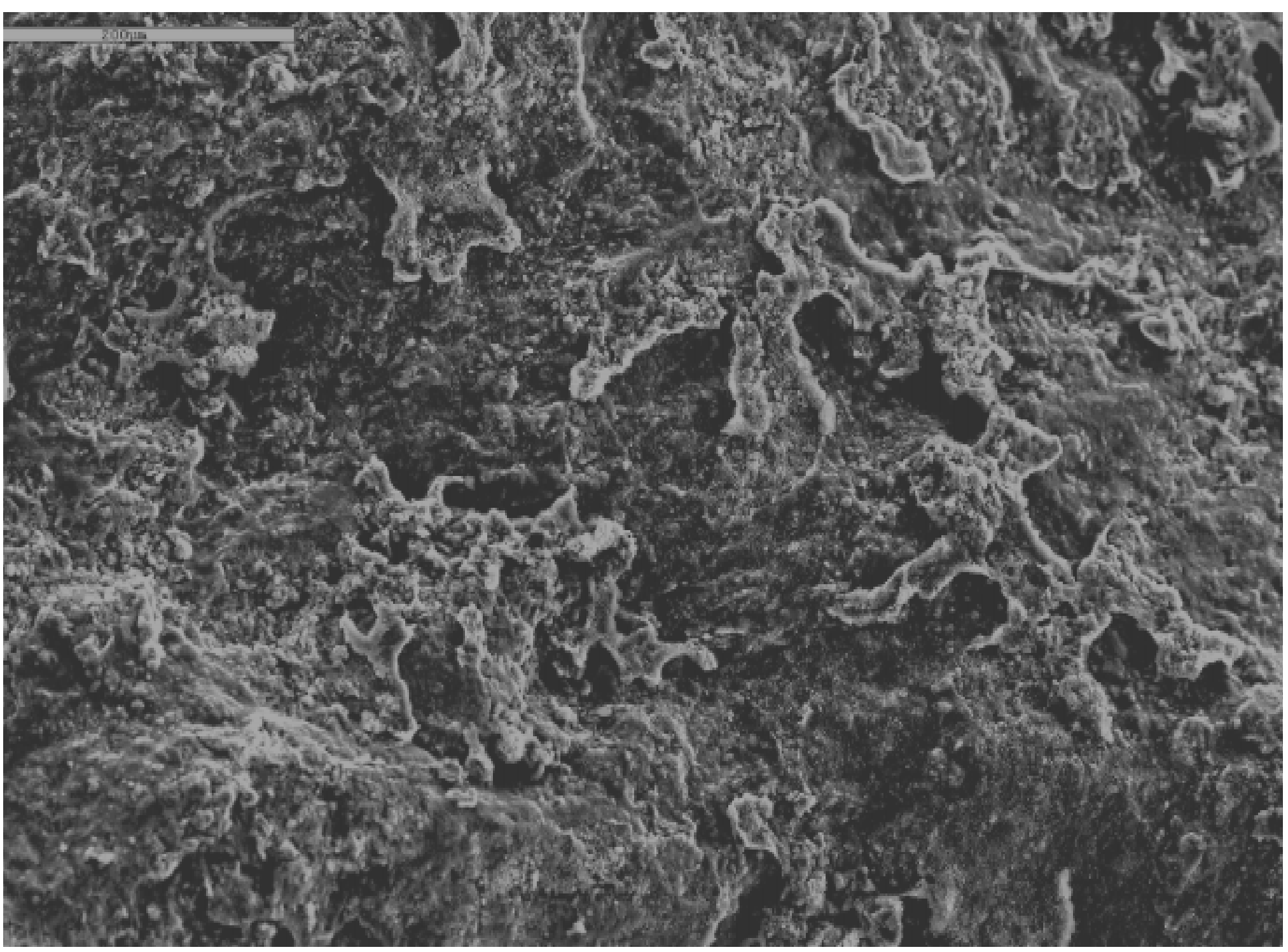

Figure 4-1 


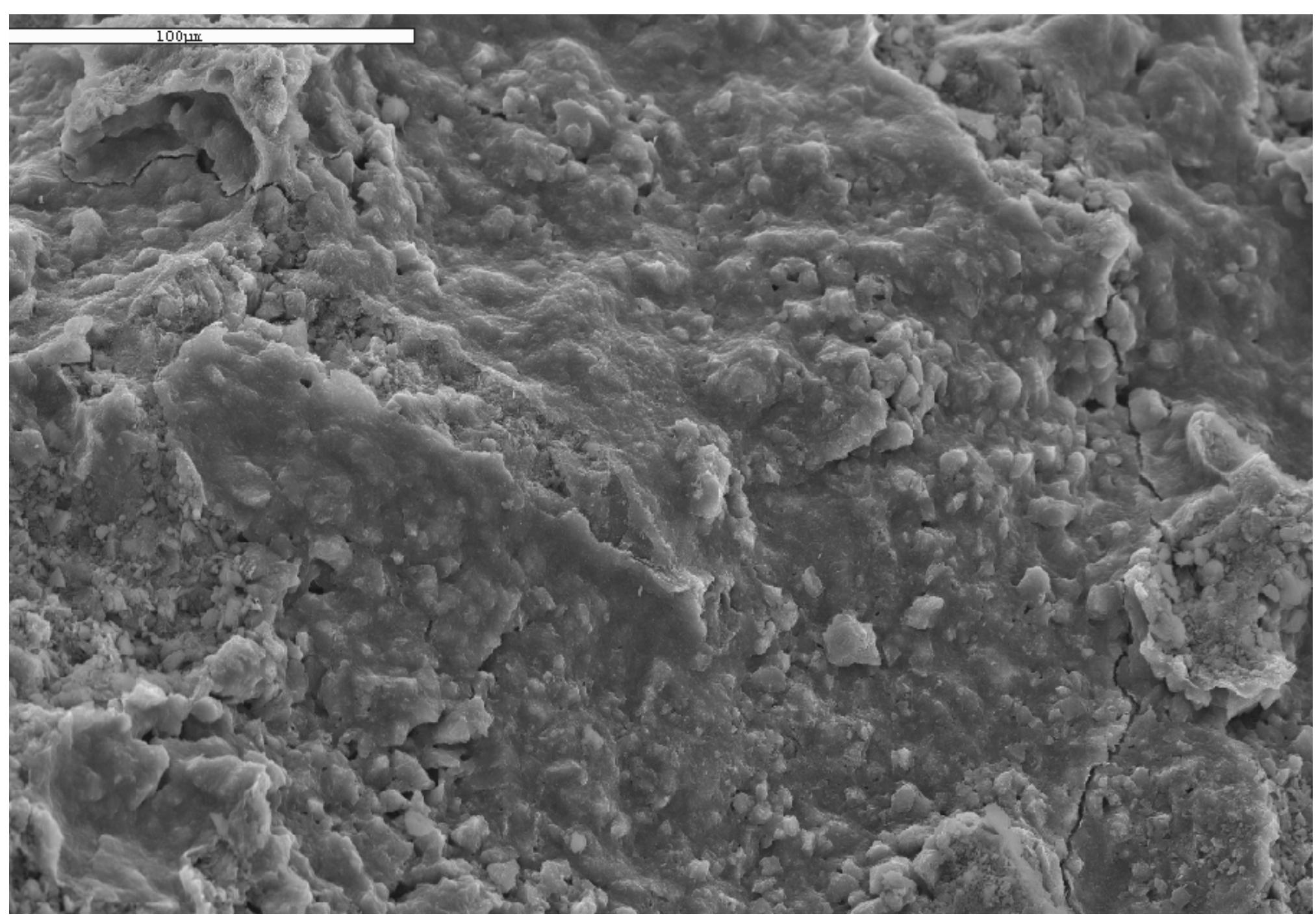

Figure 4-2

Fracture Surface with Illite/Smectite Clay "Mat,"

Cracks Where Bridging Ribs in the Clay Mat have Pulled Away from Fracture Surface (2,236 foot depth) 


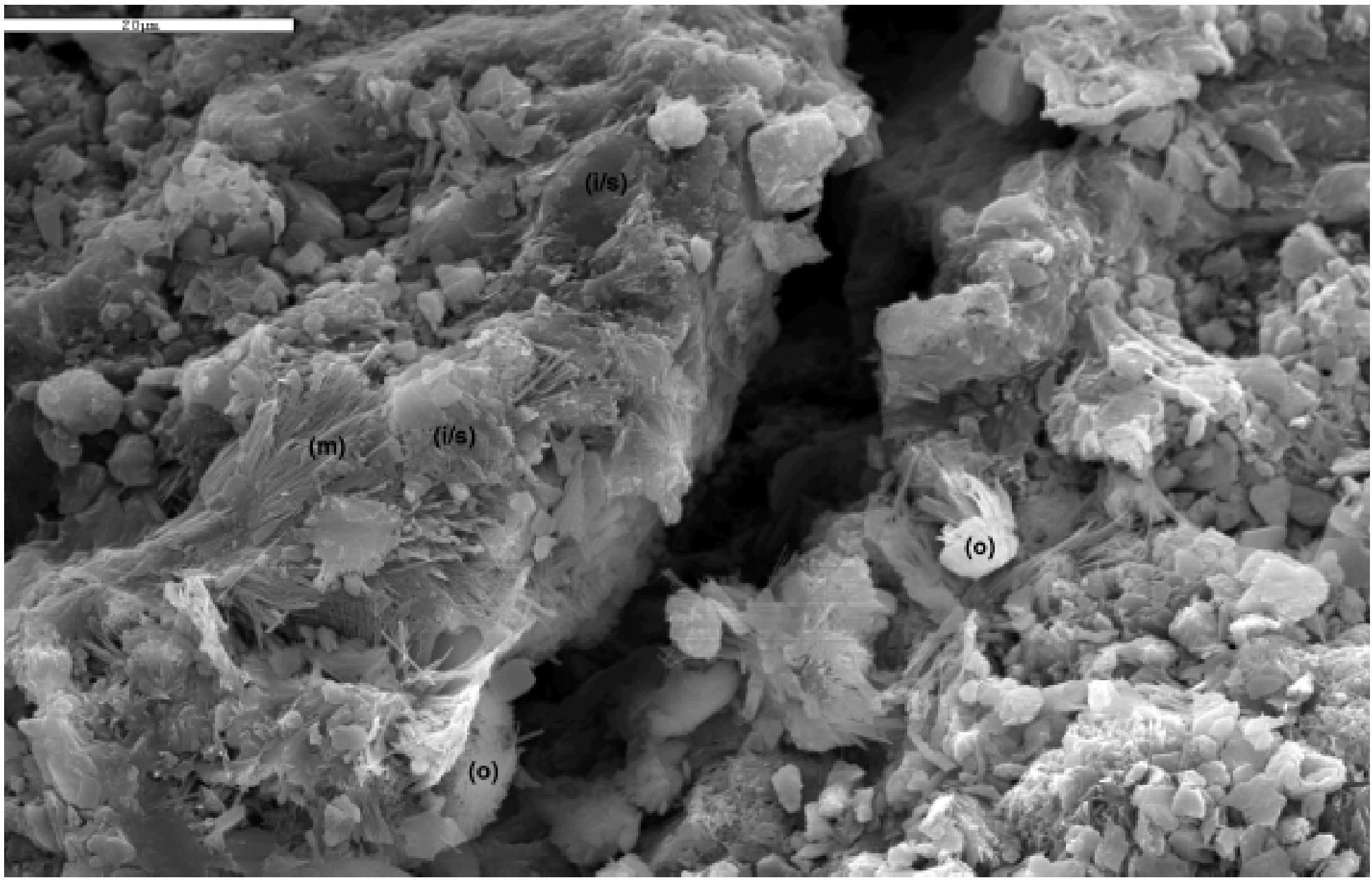

Figure 4-3

"Clean" Fracture Cutting Illite/Smectite Clay "Mat" (i/s), Opaline Silica (o), and Mordenite $(m)$ on Natural Fracture Surface $(2,236$ foot depth) 


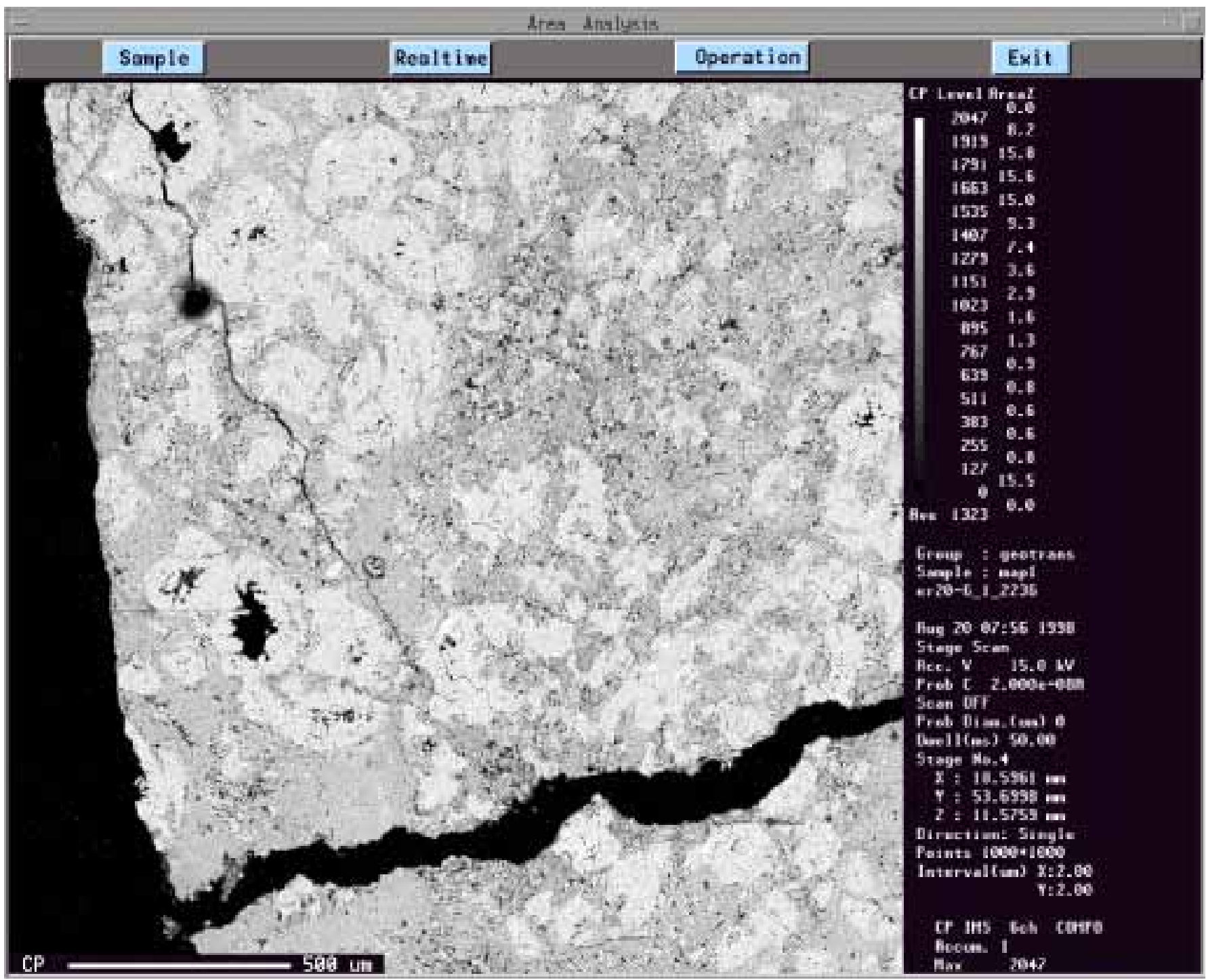

Figure 4-4

Backscatter Image (2,236 foot depth) 
Table 4-1

Electron microprobe results (in weight percent oxide) for point analyses of specific phases in ER-20-6\#1 drill core samples

\begin{tabular}{|c|c|c|c|c|c|c|c|c|c|c|c|c|}
\hline Sample Description & $\mathrm{Na}_{2} \mathrm{O}$ & $\mathrm{MgO}$ & $\mathrm{Al}_{2} \mathrm{O}_{3}$ & $\mathrm{SiO}_{2}$ & $\mathrm{~K}_{2} \mathrm{O}$ & $\mathrm{CaO}$ & $\mathrm{FeO}$ & MnO & $\mathrm{TiO}_{2}$ & $\mathrm{BaO}$ & Sro & Total \\
\hline 2851.5B - alkali feldspar & 3.00 & ND & 18.60 & 65.81 & 12.07 & 0.21 & 0.09 & ND & ND & ND & ND & 99.78 \\
\hline 2851.5B - glass & 2.84 & ND & 12.26 & 77.76 & 6.47 & 0.21 & 0.15 & ND & ND & ND & ND & 99.69 \\
\hline 2851.5B - plagioclase & 8.48 & ND & 22.39 & 63.36 & 1.23 & 3.79 & 0.11 & ND & ND & ND & ND & 99.36 \\
\hline 2851.5B - alkali feldspar & 3.12 & ND & 18.40 & 66.83 & 11.47 & 0.16 & 0.08 & ND & ND & ND & ND & 100.06 \\
\hline 2236B - alkali feldspar & 3.26 & ND & 18.84 & 65.81 & 11.55 & 0.20 & 0.07 & ND & ND & ND & ND & 99.73 \\
\hline $2236 \mathrm{~B}$ - clay mat & 0.68 & 0.09 & 7.92 & 41.69 & 1.86 & 0.70 & 1.24 & ND & 0.12 & ND & ND & 54.30 \\
\hline $2236 \mathrm{~B}$ - clay mat & 1.08 & 0.08 & 7.43 & 41.62 & 2.40 & 0.72 & 1.04 & ND & 0.07 & ND & ND & 54.44 \\
\hline 2236B - zeolite & 2.29 & ND & 12.99 & 72.60 & 3.87 & 1.12 & ND & ND & ND & ND & ND & 92.87 \\
\hline $\begin{array}{l}\text { 2835B - alkali feldspar } \\
\text { rim on quartz }\end{array}$ & 3.95 & ND & 18.44 & 68.49 & 10.07 & 0.17 & 0.06 & ND & ND & ND & 0.34 & 101.52 \\
\hline 2835B - Fe-oxyhydroxide & ND & 0.05 & 1.28 & ND & ND & ND & 87.91 & 2.26 & 0.94 & ND & 0.06 & 92.50 \\
\hline 2835B - plagioclase & 8.54 & ND & 22.39 & 63.38 & 1.06 & 4.01 & 0.17 & ND & ND & ND & 0.39 & 99.94 \\
\hline $\begin{array}{l}\text { 2835B - alkali feldspar } \\
\text { rim on quartz }\end{array}$ & 3.34 & ND & 18.57 & 68.77 & 10.48 & 0.10 & 0.13 & ND & ND & ND & 0.40 & 101.79 \\
\hline
\end{tabular}

Replicate analyses of standards indicate a relative analytical precision of better than \pm 1 percent (1) for major elements and a precision equal to counting statistics for minor elements. Detection limits are typically 0.05 weight percent for all elements except for $\mathrm{BaO}$ which is 0.2 weight percent. No microprobe analyses were conducted on sample $2812 \mathrm{~B}$ as it is assumed to be equivalent to sample 2835B. ND = not detected, below detection limit of instrument.

As shown in Figure 4-4, the backscatter image shows 3 prominent fractures in this sample: the open fracture surface is shown as a near vertical feature along the left hand margin of the field of view; a fracture, with an aperture of approximately 50 to 70 microns, is approximately normal to the open fracture surface and appears open and unrestricted in this field of view (although it may be necking down from left to right); and, a thin (approximately 5 to 10 microns) irregular fracture that originates near the upper left hand corner of the field of view and appears to die out in the lower left center of the sample. The backscatter image also shows numerous partially to fully filled vugs, 200 to 300 microns in diameter.

The elemental maps show the gross distribution of mineral phases in the sample. The col or intensity (as shown by the col or bar in the upper right-hand corner of the figure) is a function of the magnitude of the $x$-ray response for the $K$ wavelength of a particular el ement for any area (a function of minimum pixel size) of the sample. The silica map (F igure 4-5) shows the zeolite phase both in the sample groundmass and as a vug filling (indicated by a dark orange to reddish orange color) and opaline silica in the groundmass (indicated by a purplish pink color). The clay mat is indicated on the silica map by the blue to bluish-green selvage along fracture surfaces. The al uminum map (Figure 4-6),similarly shows the zeolite phase (in red to pinkish red) 


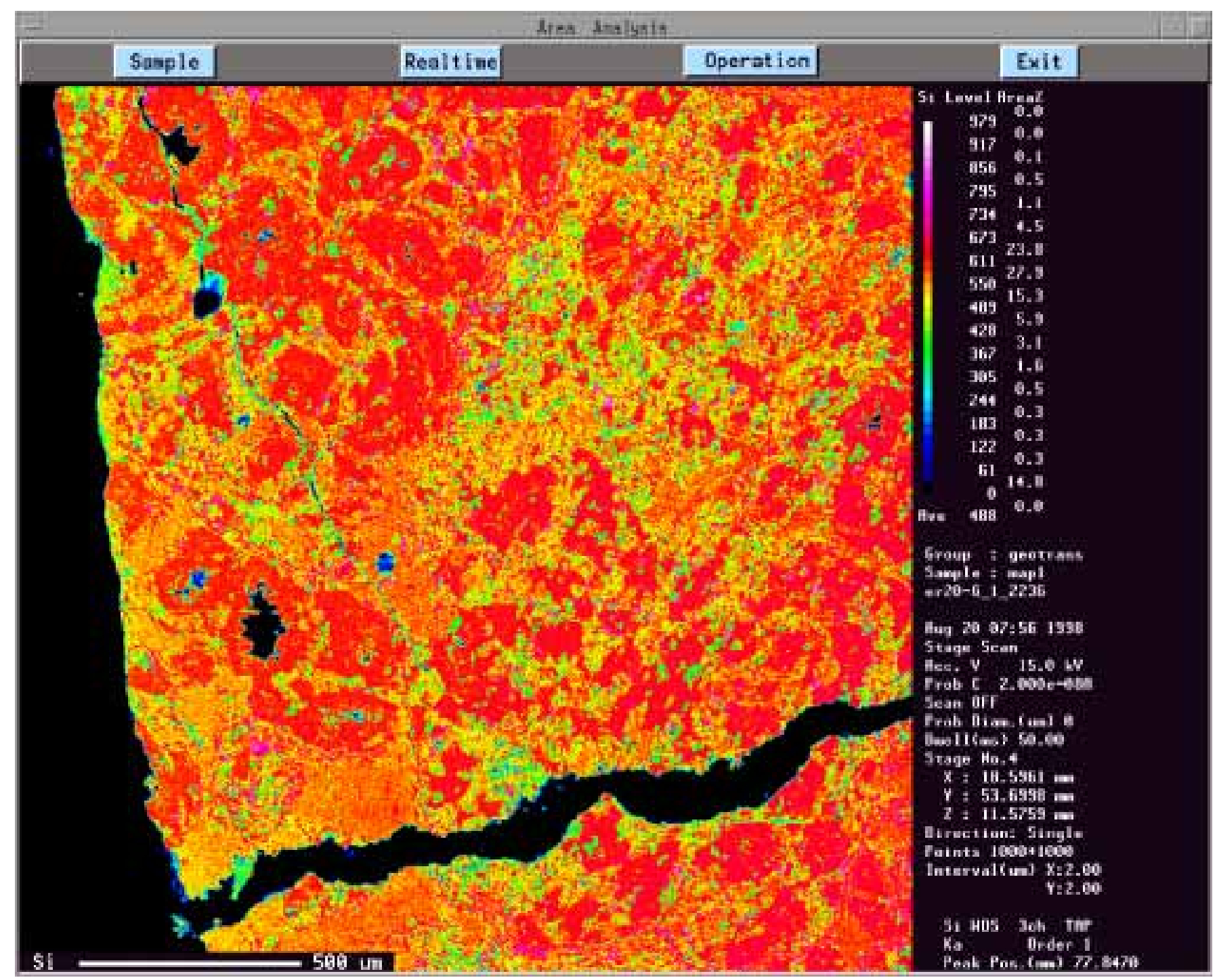

Figure 4-5

Elemental Map for Silica (2,236 foot depth) 


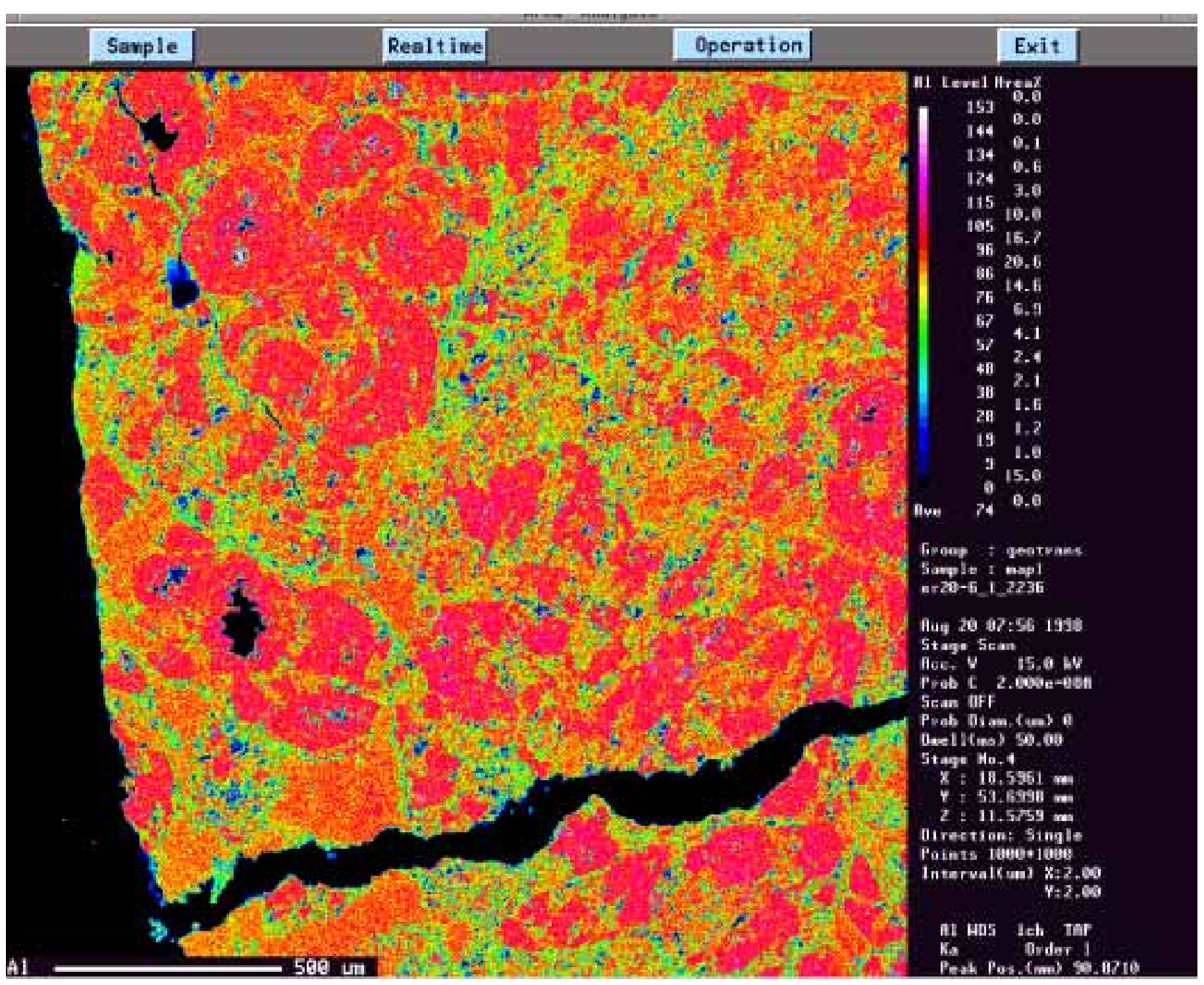

$590 \mathrm{~m}$ in
Figure 4-6

Elemental Map for Aluminum (2,236 foot depth) 
and the clay mat along the fracture surfaces (in blue to bluish-green). The potassium map (Figure 4-7), shows the presence of biotite (in yellow to orange) but is generally of low abundance in this sample. Calcium (F igure 4-8), is of very low abundance in this sample, no specific calcium bearing phases were identified. Similarly iron (Figure 4-9), is of generally low abundance in this sample, showing some degree of correspondence to potassium distribution (reflecting biotite) and also possibly reflecting an oxide phase that has not been identified yet.

Four electron microprobe quantitative point analyses are included in Table 4-1. Two separate analyses of the clay 'mat' indicate it to be an alumino-silicate with significant $\mathrm{Na}, \mathrm{K}, \mathrm{Ca}$, and Fe leaving approximately 45 percent unaccounted. This could be due to the effects of porosity, the presence of water, or elements not analyzed. A representative analysis of the vug-filling zeolite phase indicate it to be a $\mathrm{K}, \mathrm{Na}, \mathrm{Ca}$-bearing alumino-silicate with approximately seven percent by weight water. The relatively low water content and relatively high silica content of this phase have made specific identification of this phase based on composition and morphology somewhat problematic (Gottardi and Galli, 1985). X-ray diffraction analysis would be required for a more conclusive identification to be made. An analysis was also conducted of an alkali feldspar crystal in the sample groundmass.

\subsection{Sample 2812B}

Existing information (Prothro et al, 1997) has described this material as a devitrified lava from the lava flow aquifer of the Calico Hills Formation. Fracture density is indicated to be 1 to 2 fractures per foot of core. Texturally and mineralogically, the sample has been described (Prothro et al, 1997) as having medium angle flow banding with conspicuous vesicles to $2 \mathrm{~cm}$ and containing rare phenocrysts of feldspar and quartz and rare biotite. This particular sample lacks visible vesicles and has one exposed open fracture face which is the focus of this activity.

\subsubsection{Optical Petrography}

This rock consists of a flow banded matrix of ( 0.025 to 0.05 millimeter) quartz, potassium feldspar, biotite, and opaque minerals with phenocrysts of quartz (up to 1.0 millimeter) and potassium feldspar (up to $0.5 \times 1.0$ millimeter). The matrix feldspars throughout the sample are typically quite ragged and intimately intergrown with clay minerals (illite?). Clay minerals are also present along flow bands and as spherulitic growths and void fillings. Some open gas cavities are present, but appear to represent a very small ( $<3$ percent) proportion of the sample. 


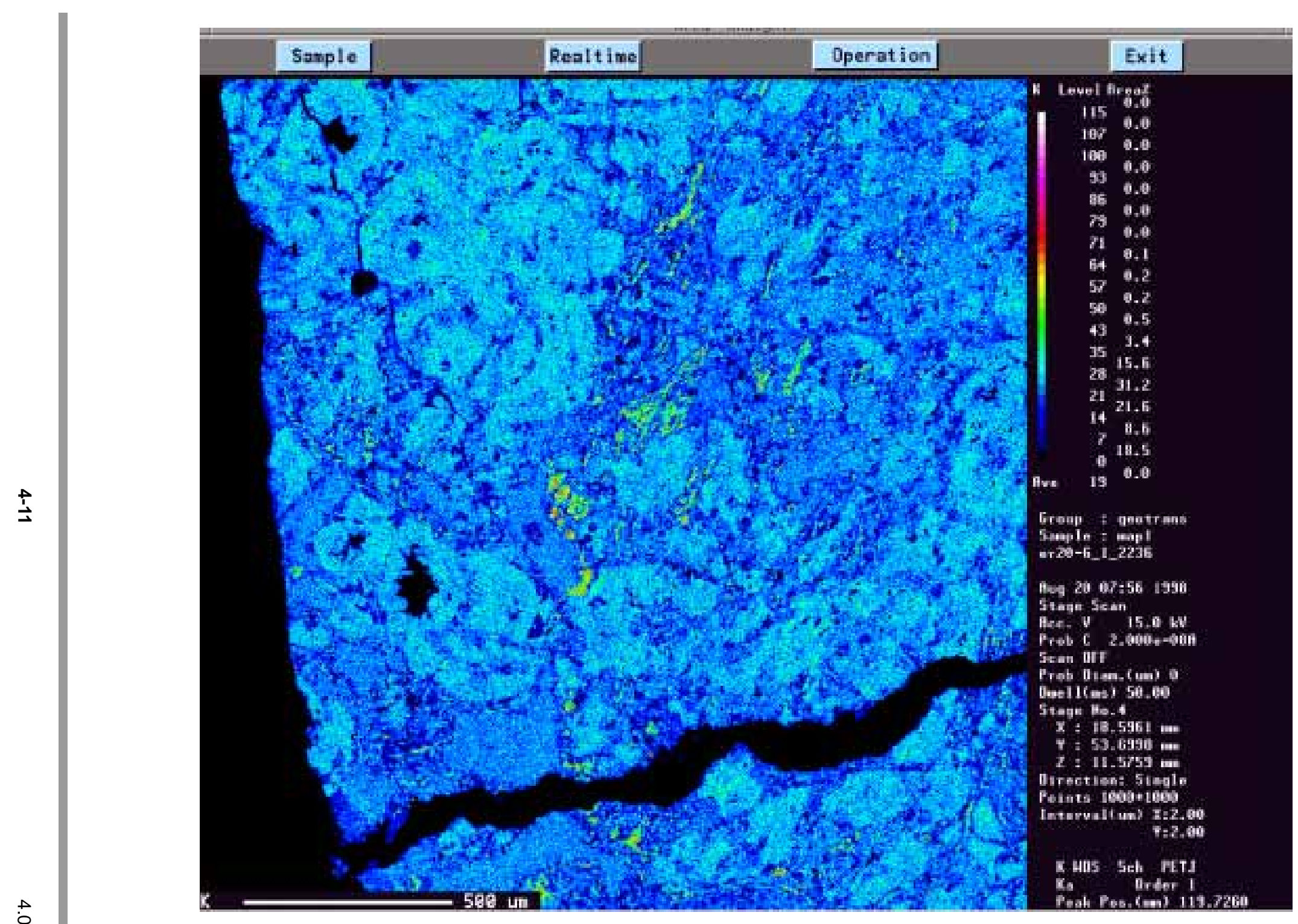

Figure 4-7

Elemental Map for Potassium (2,236 foot depth) 


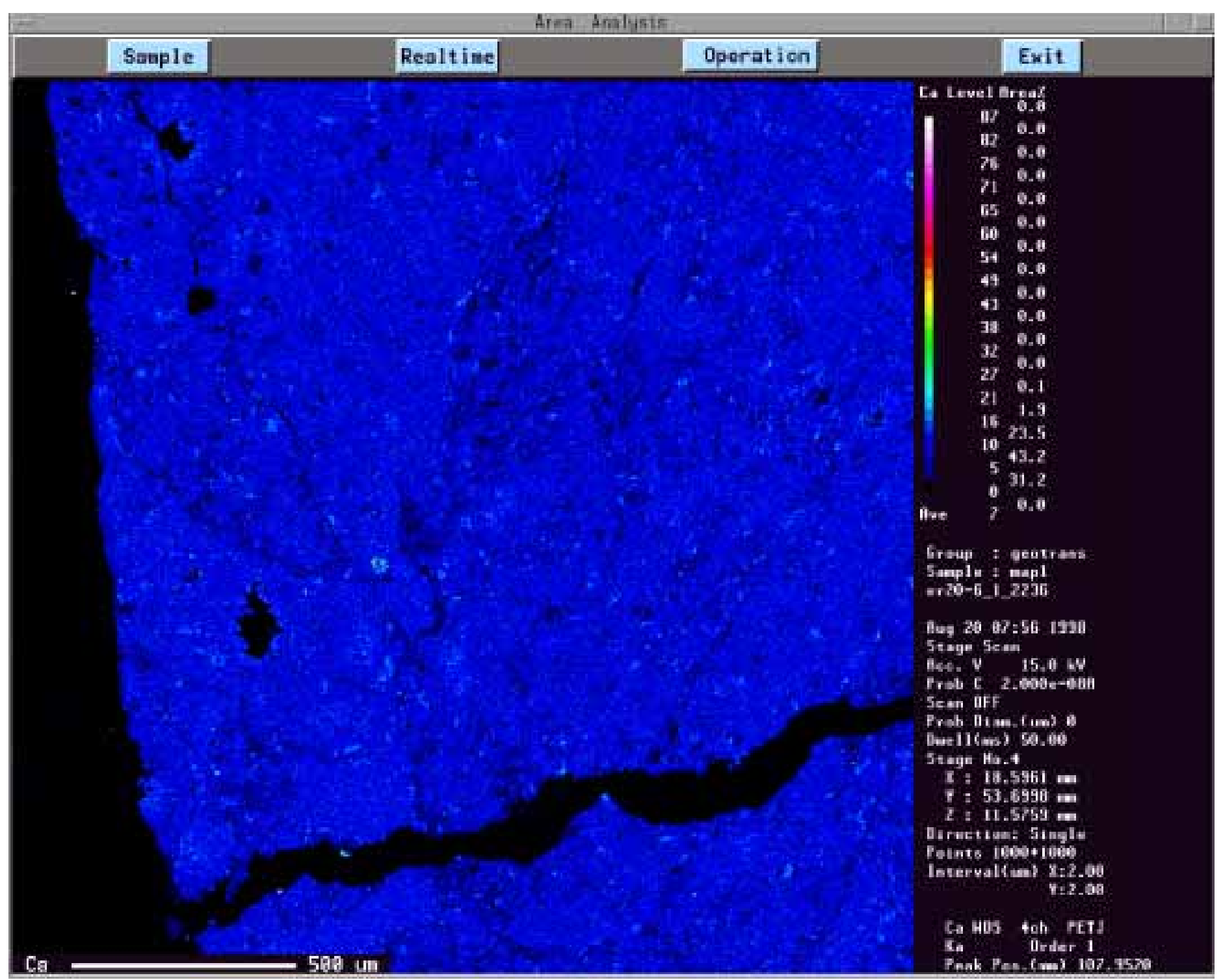

Figure 4-8

Elemental Map for Calcium (2,236 foot depth) 

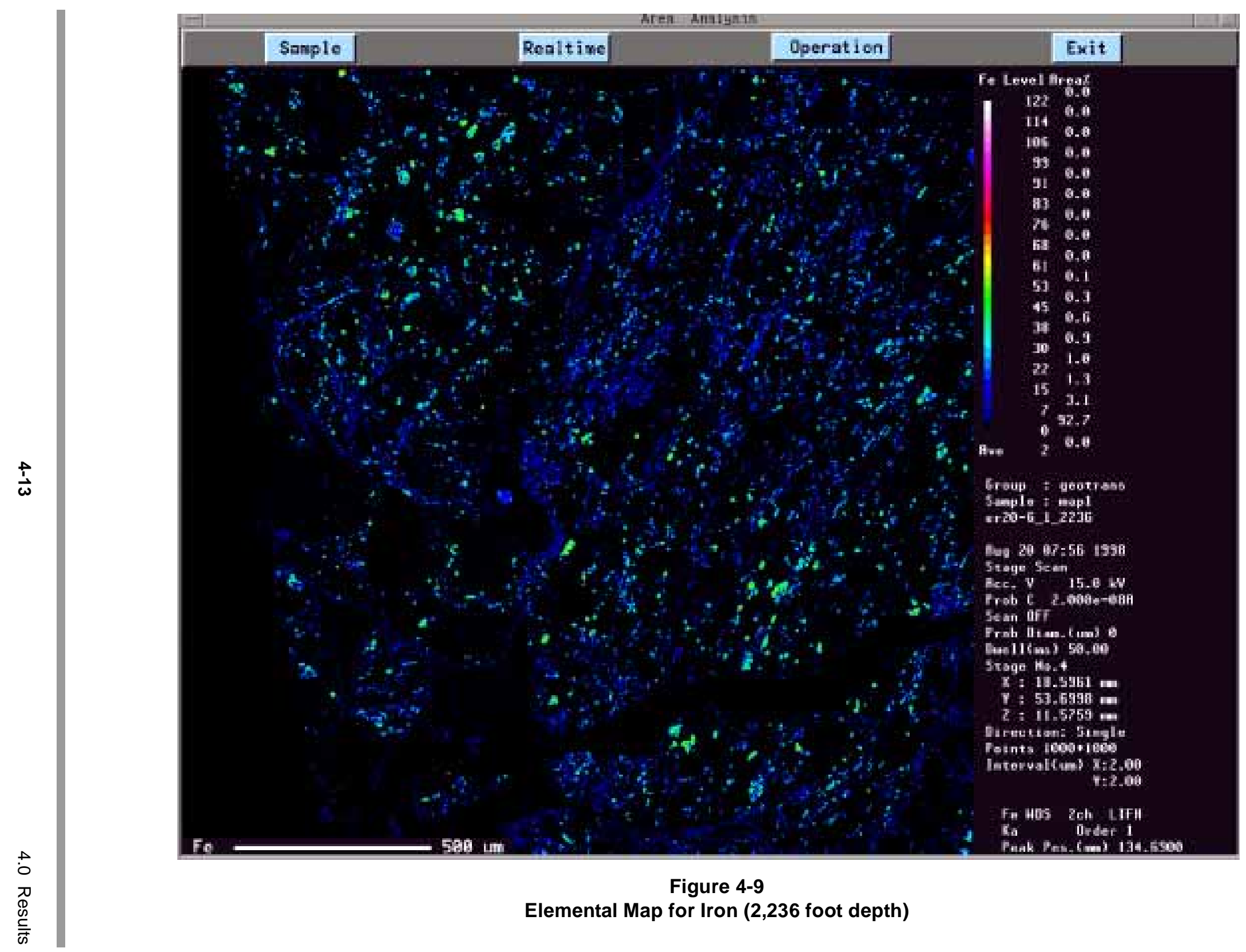

Figure 4-9

Elemental Map for Iron (2,236 foot depth) 
There is a single style of fracture development evident in thin section. The open fracture face exposed on the sample surface is mimicked by a subparallel set of internal fractures within the sample. Fractures in this sample exist at a high angle (70 to 90 degrees) to the well devel oped flow banding.

Petrographic examination of this sample indicates that the exposed fracture surface appears to be lacking any clearly visible secondary mineral assemblage. The subparallel fractures are typically irregular, less than 0.05 millimeter in aperture and locally blocked with a very-fine grained ( $<0.002$ millimeter) mixture of locally iron-oxide stained clay minerals ( \pm zeolite?).

\subsubsection{Scanning Electron Microscopy}

SE M analysis of the exposed fracture surface (F igure 4-10) reveals well devel oped flow alignment in feldspar and quartz crystals with localized secondary mineral phases. As shown in Figure 4-11, the localized secondary minerals are comprised of a mixed illite/smectite clay mat and opaline silica. The potassium feldspar crystals are the predominant groundmass phase and are commonly altered to illite (Figure 4-12). Quartz is less common in the groundmass (Figure 4-13), but is the predominant phenocryst phase. Illite (predominantly after feldspar) is common, and occurs both after feldspar and as discrete aggregates growing upon and interstitial to groundmass crystalites. Illite covers approximately 46 percent of the of the fracture surface. The illite after feldspar observed with the SEM appears to be the same clay mineral phase seen to be intimately intergrown with potassium feldspar in thin section. Primary quartz and potassium feldspar comprise 29 percent and 25 percent, respectively, of the fracture surface.

\subsubsection{Electron Microprobe}

A thin section transecting the exposed fracture surface also contains a discontinuous subparallel fracture as shown in the backscatter image (F igure 4-14) which reveals the textural and structural relationships within the field of view. The microprobe analysis of this thin section also provided five elemental maps (one each for $\mathrm{Si}, \mathrm{Al}, \mathrm{K}, \mathrm{Ca}$, and $\mathrm{Fe}$; Figures 4-15, 4-16, 4-17, 4-18, and 4-19, respectively) for the same area shown in the backscatter image. In addition, several quantitative point analyses of discrete phases present in the thin section were performed and are summarized in Table 4-1.

In Figure 4-14, the backscatter image shows the prominent open fracture surface $(A)$ as a near vertical feature along the left hand margin of the field of view and a subparallel fracture (B) that originates 

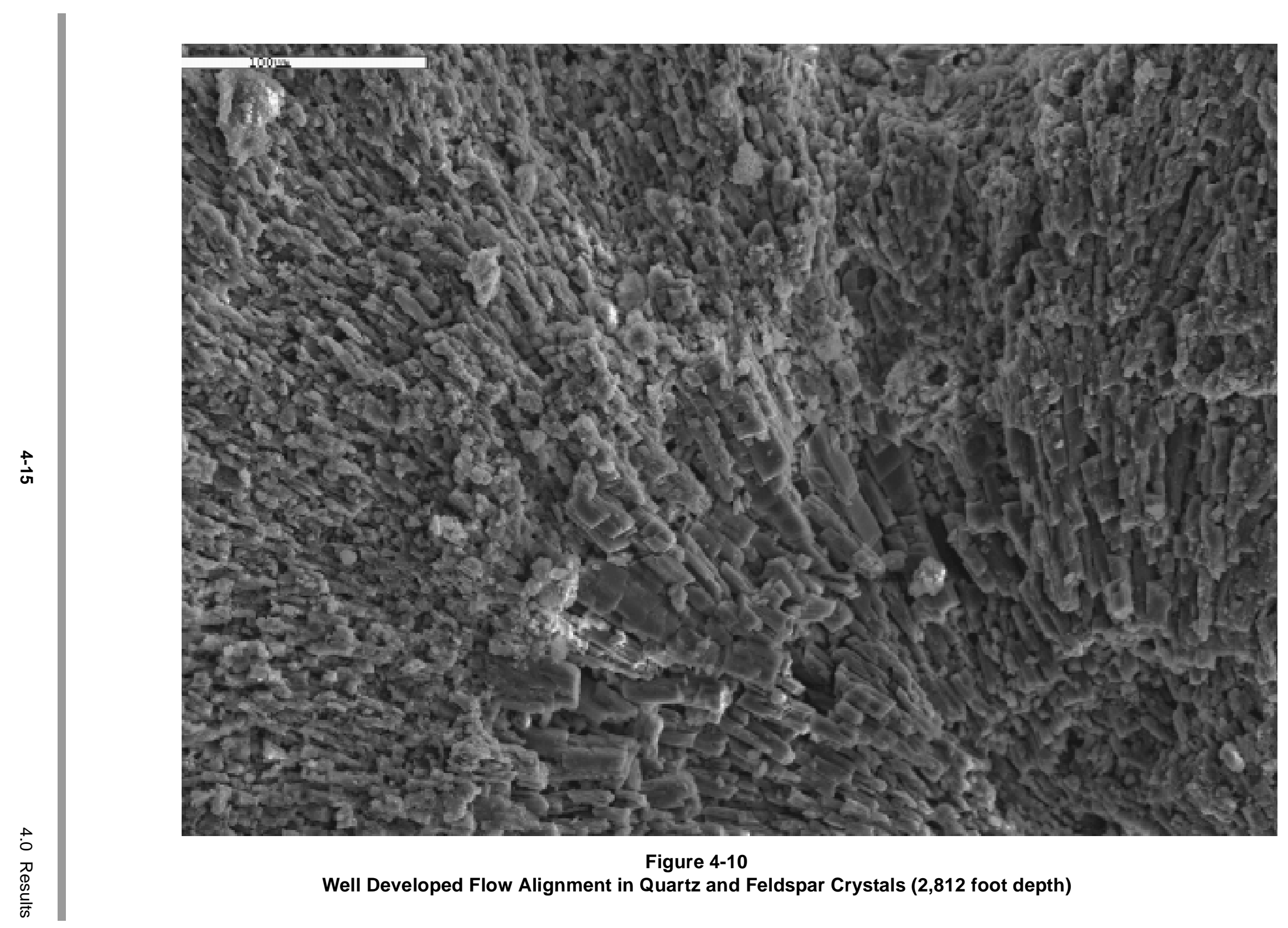

Figure 4-10

Well Developed Flow Alignment in Quartz and Feldspar Crystals (2,812 foot depth) 


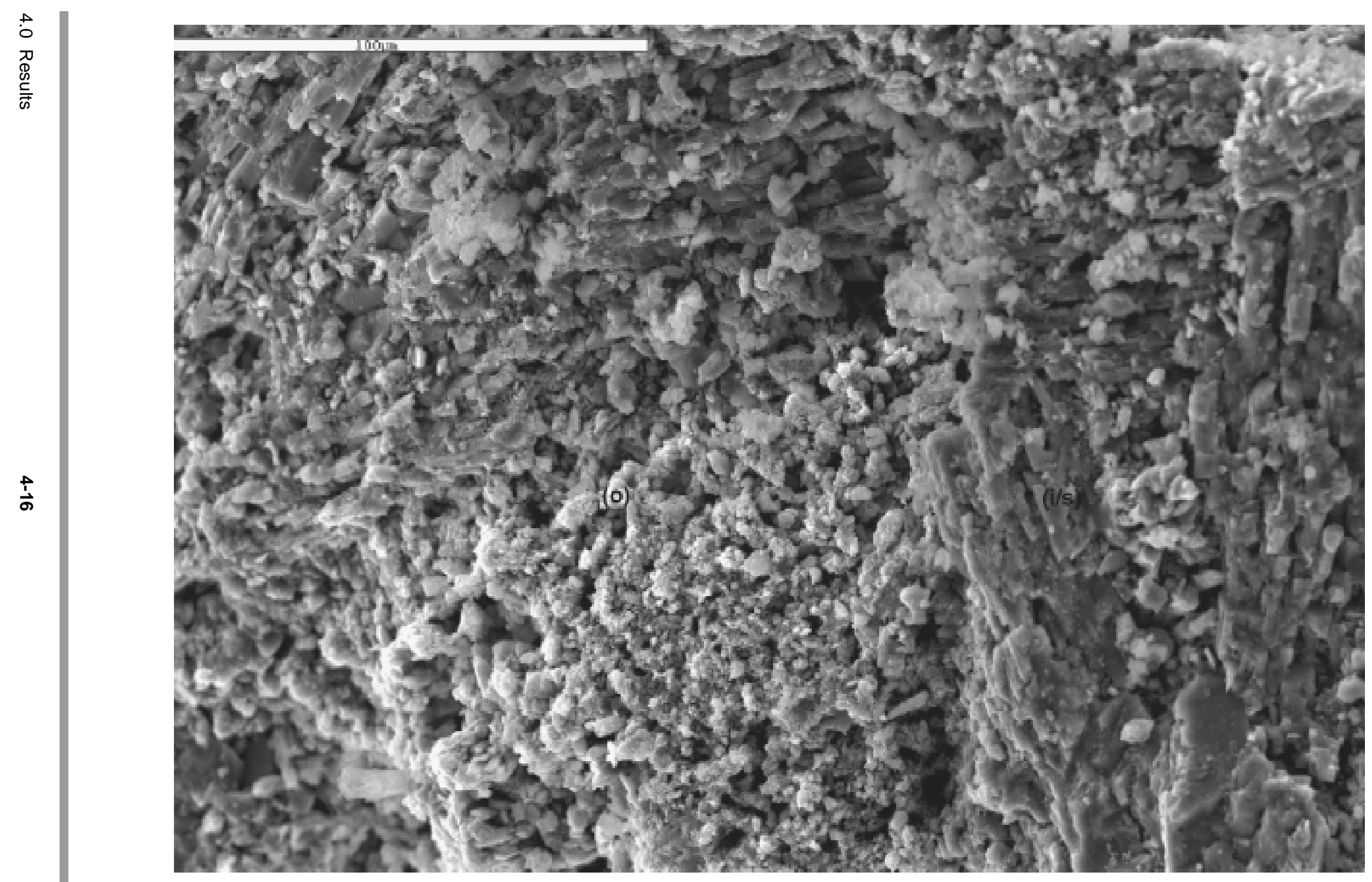

Figure 4-11

Illite/Smectite (i/s) Clay "Mat" and Opaline Silica (o) (2,812 foot depth) 

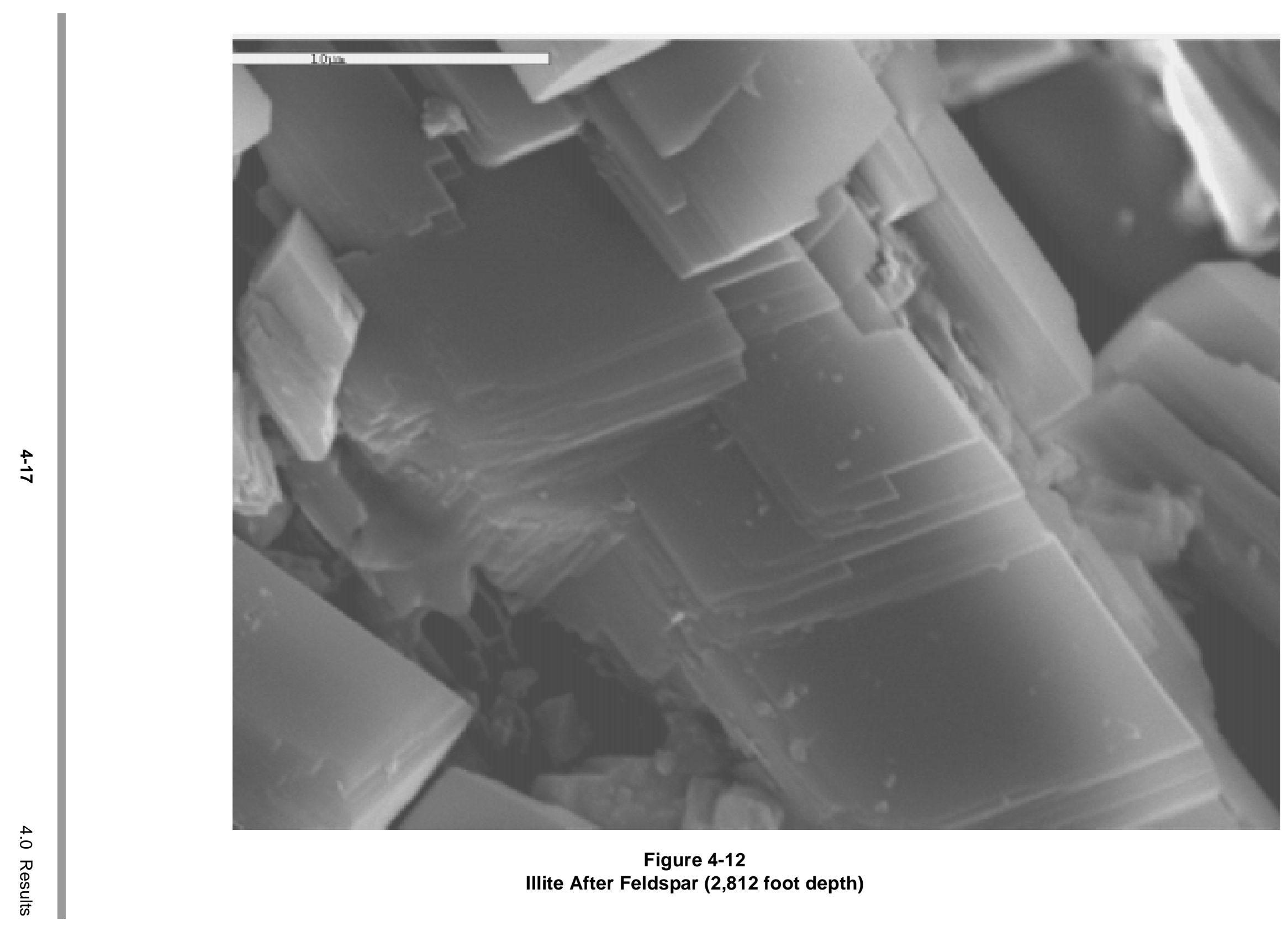

Figure 4-12

Illite After Feldspar (2,812 foot depth) 


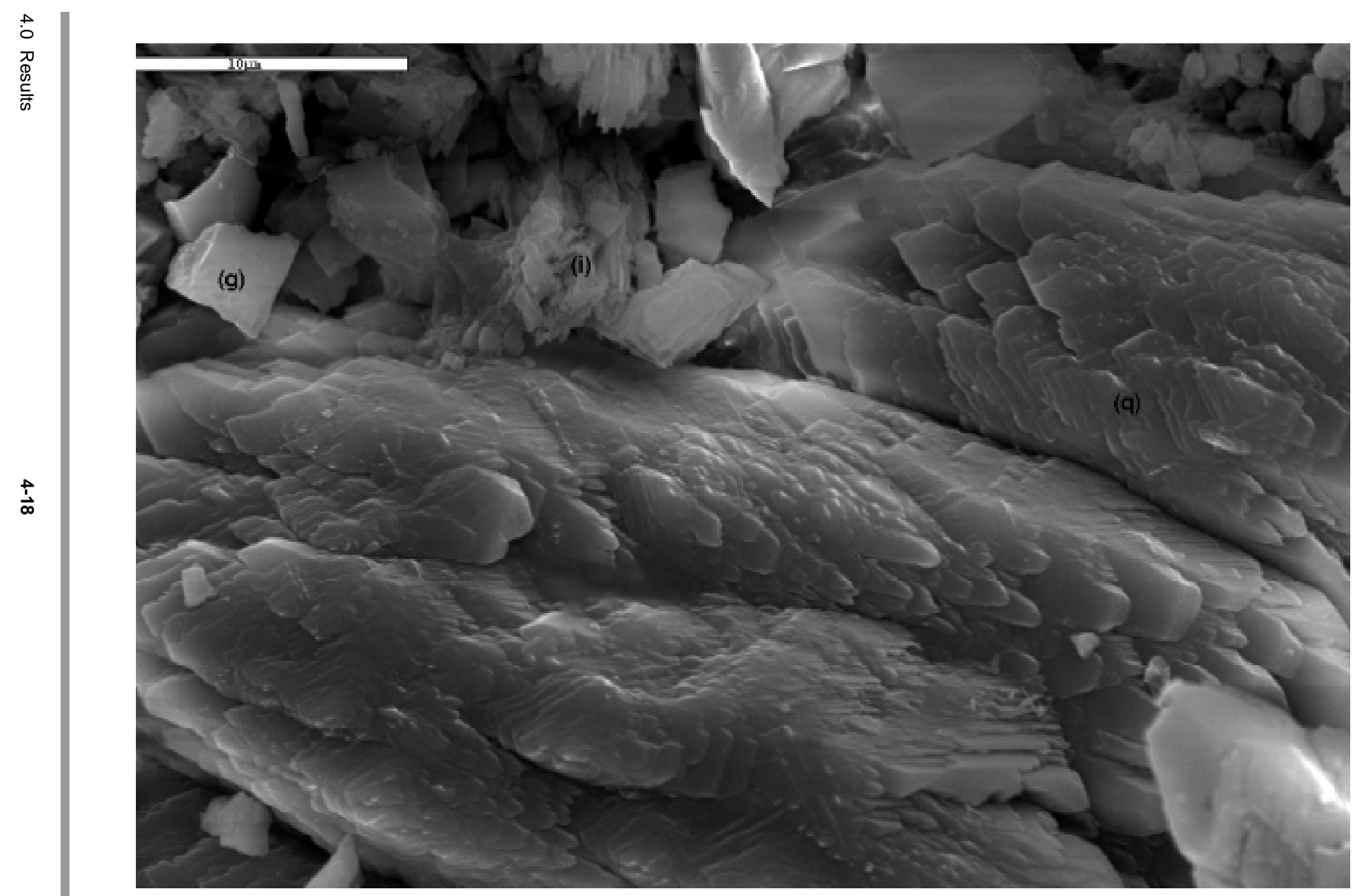

Figure 4-13

Matrix Quartz (q), with Minor Illite (i) and Glass (g) (2,812 foot depth) 


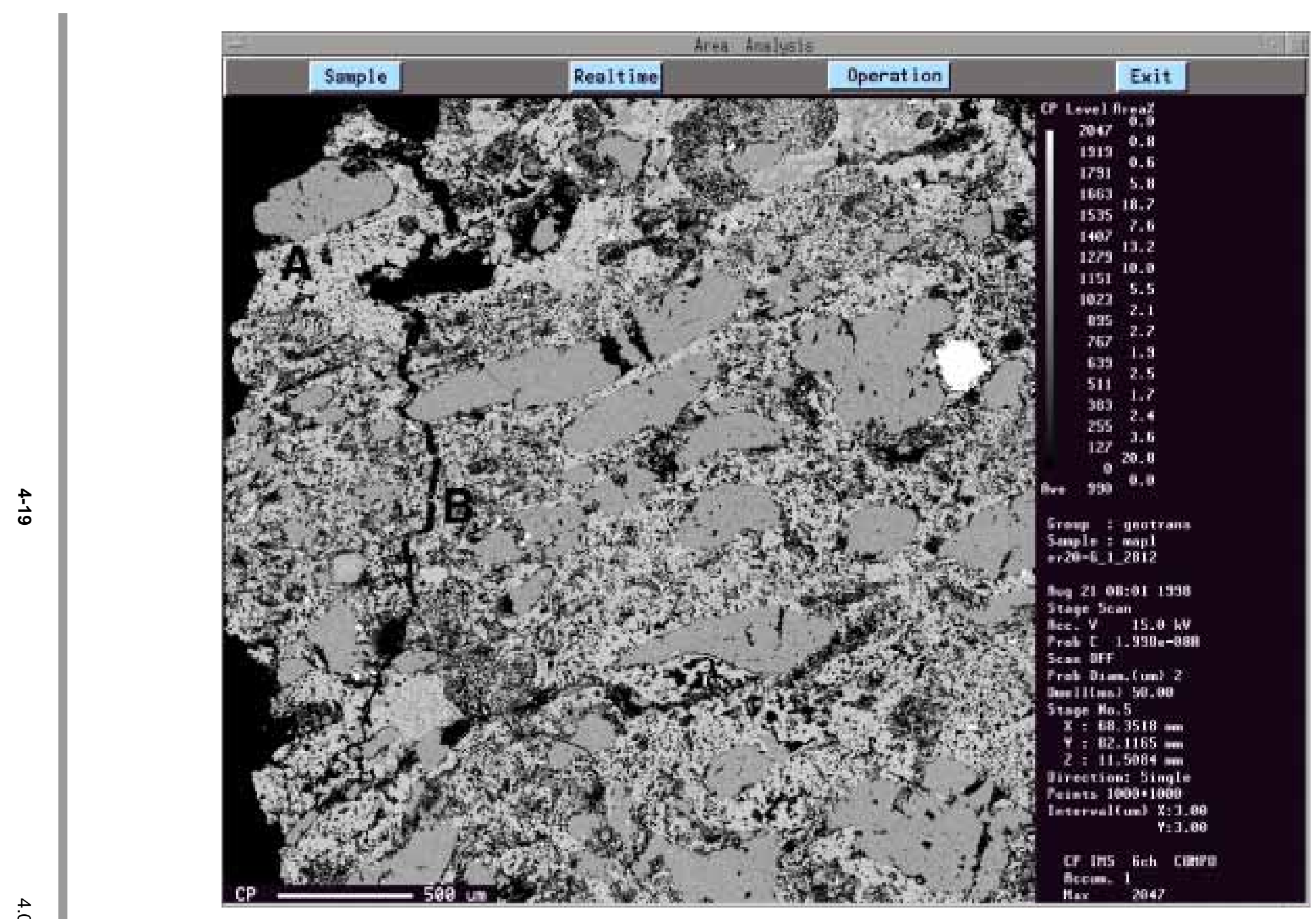

Figure 4-14

Backscatter Image (2,812 foot depth) 
near the upper left hand corner of the field of view and appears to neck down toward the lower left corner of the sample. The backscatter image clearly shows the abundant quartz phenocrysts in the sample.

The elemental maps show the gross distribution of mineral phases in the sample. The silica map (Figure 4-15), shows the quartz phenocrysts (indicated by the purplish pink color) and volcanic glass in the groundmass (indicated by the red to reddish orange col or). The day devel opment along fracture surfaces is indicated on the silica map by the blue to bluish-green selvage. The presence of thin sub-linear, blue to bluish-green veinlets on the silica map also suggests that other fractures are present in the sample that are now largely filled. A largely filled fracture (C) originates near the lower left corner of the sample and trends toward the center of the right margin. Two, irregular microfractures are also apparent: one (D) branches off from fracture (B) and trends toward the bottom center of the sample; and, the other $(E)$ transects the upper right hand corner of the sample. The low range in concentration represented on the aluminum map (F igure 4-16) contributes little to the micro-fabric details other than reinforcing the locations of the previously identified fractures. The potassium map (Figure 4-17), reflects a greater range in concentration level and clearly identifies the fractures visible in the silica map. Calcium (Figure 4-18), is of low abundance in this sample, and no specific calcium bearing phases were identified. Similarly iron (F igure 4-19), is of generally low overall abundance in this sample, however a relatively large (approximately 150 to 200 microns) iron-oxide phase is present near the upper right hand corner of the sample and also present as much finer grains disseminated throughout the sample.

No electron microprobe quantitative point analyses are included in Table 4-1 for this sample. It is assumed, based on the discussion in Prothro et al (1997), that this sample is equivalent to sample 2835B (discussed in the next section) for which quantitative analyses are included.

\subsection{Sample 2835B}

Existing information (Prothro et al, 1997) has described this material as a devitrified lava from the lava flow aquifer of the Calico Hills Formation and equivalent to sample 2812B. This particular sample is lacking visible vesicles and fractures but does have an approximately 1 $\mathrm{cm}$ thick, off-white band that is parallel to flow banding and distinct from the typically gray rock matrix. The nature of this mineralogical and/or compositional band is the focus of this activity. 

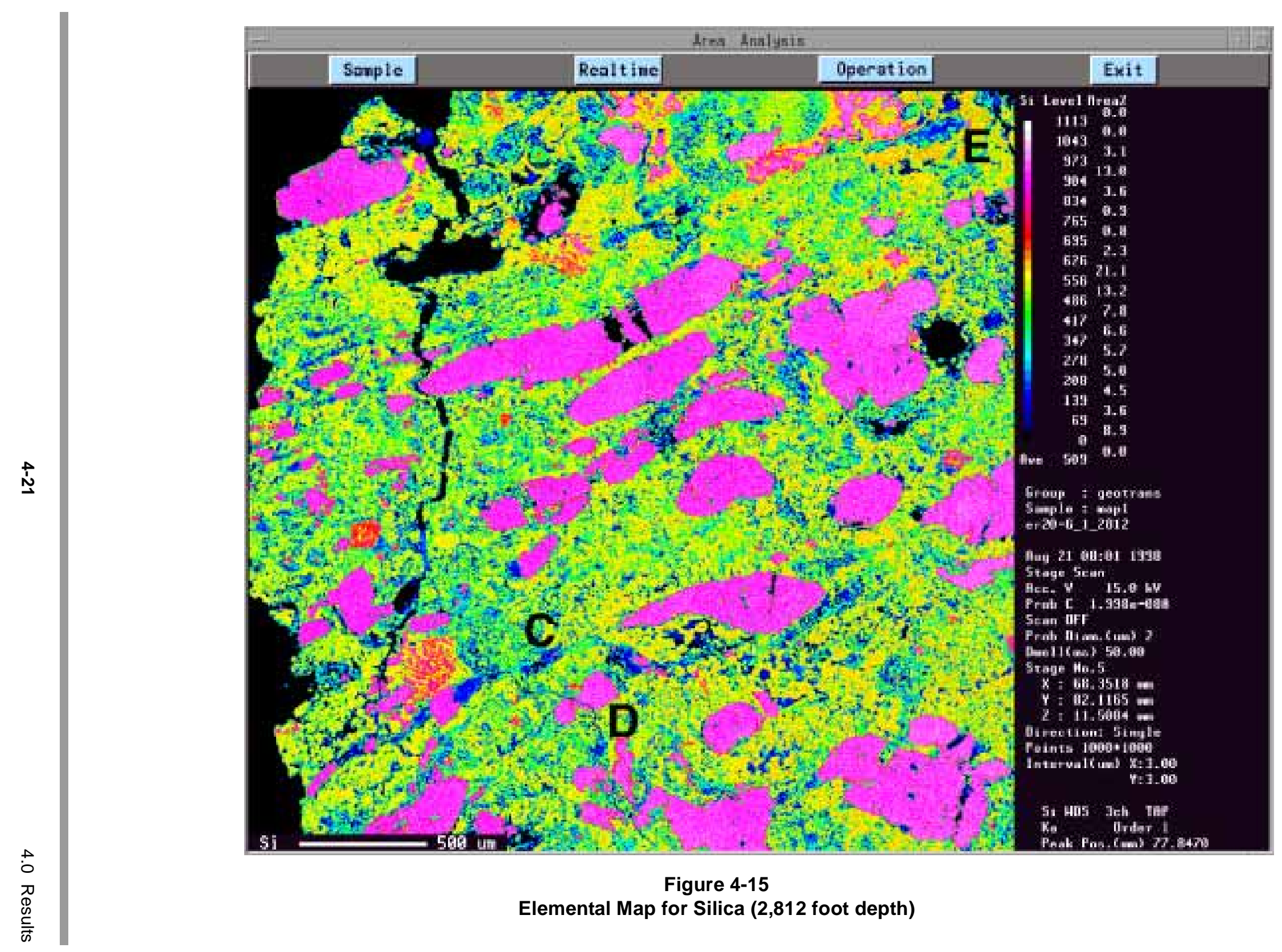

Figure 4-15

Elemental Map for Silica (2,812 foot depth) 


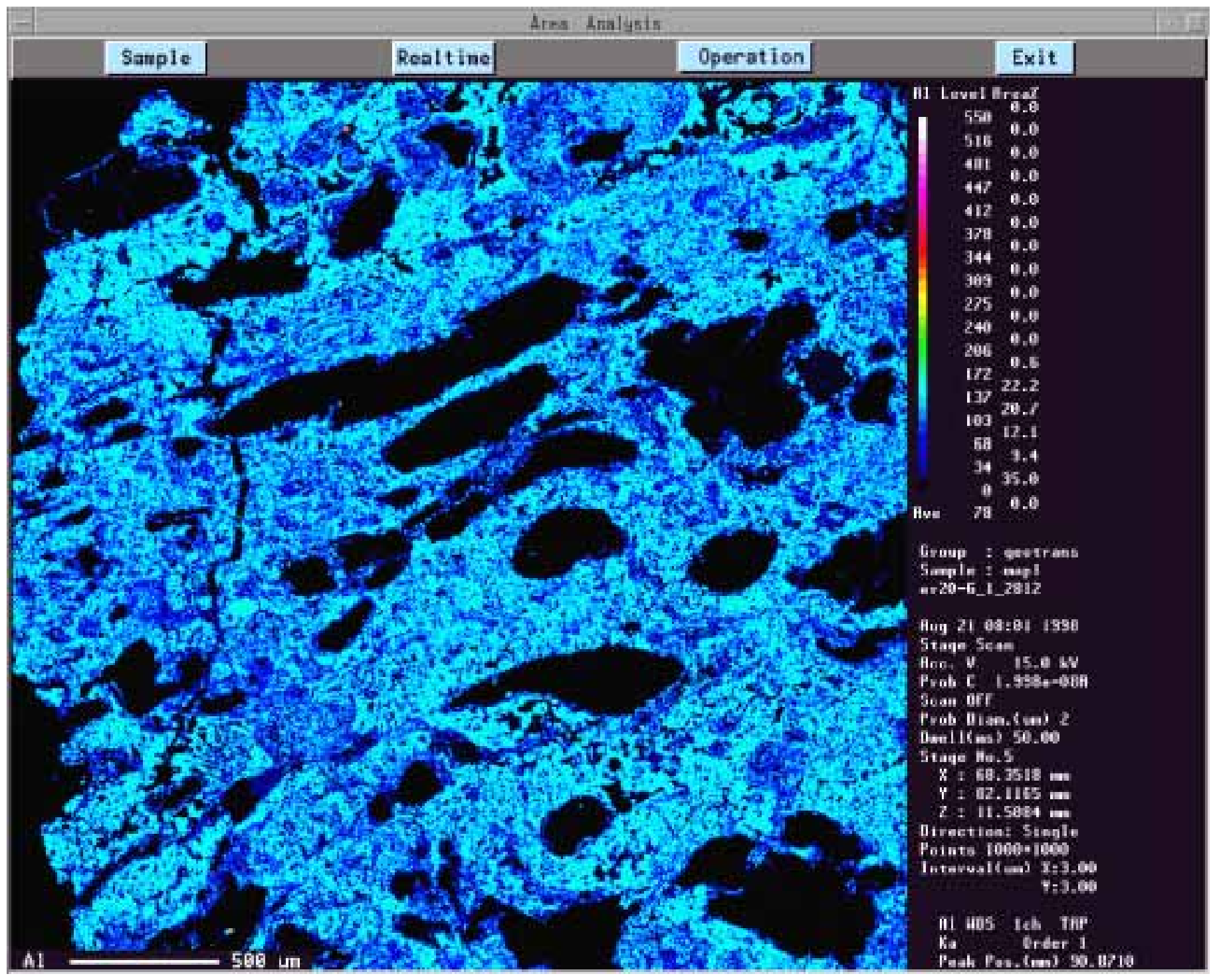

Figure 4-16

Elemental Map for Aluminum (2,812 foot depth) 


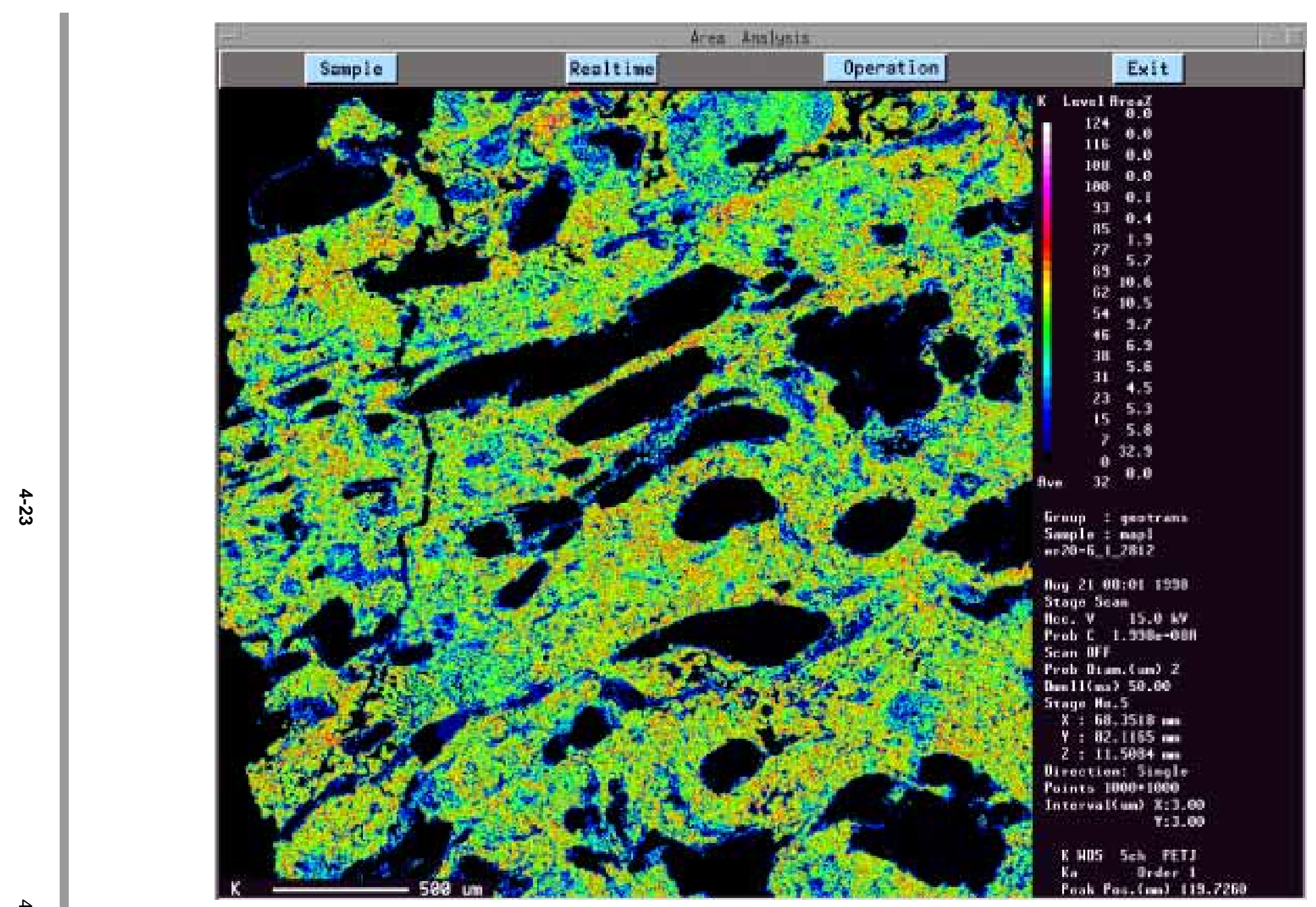

Figure 4-17

Elemental Map for Potassium (2,812 foot depth) 


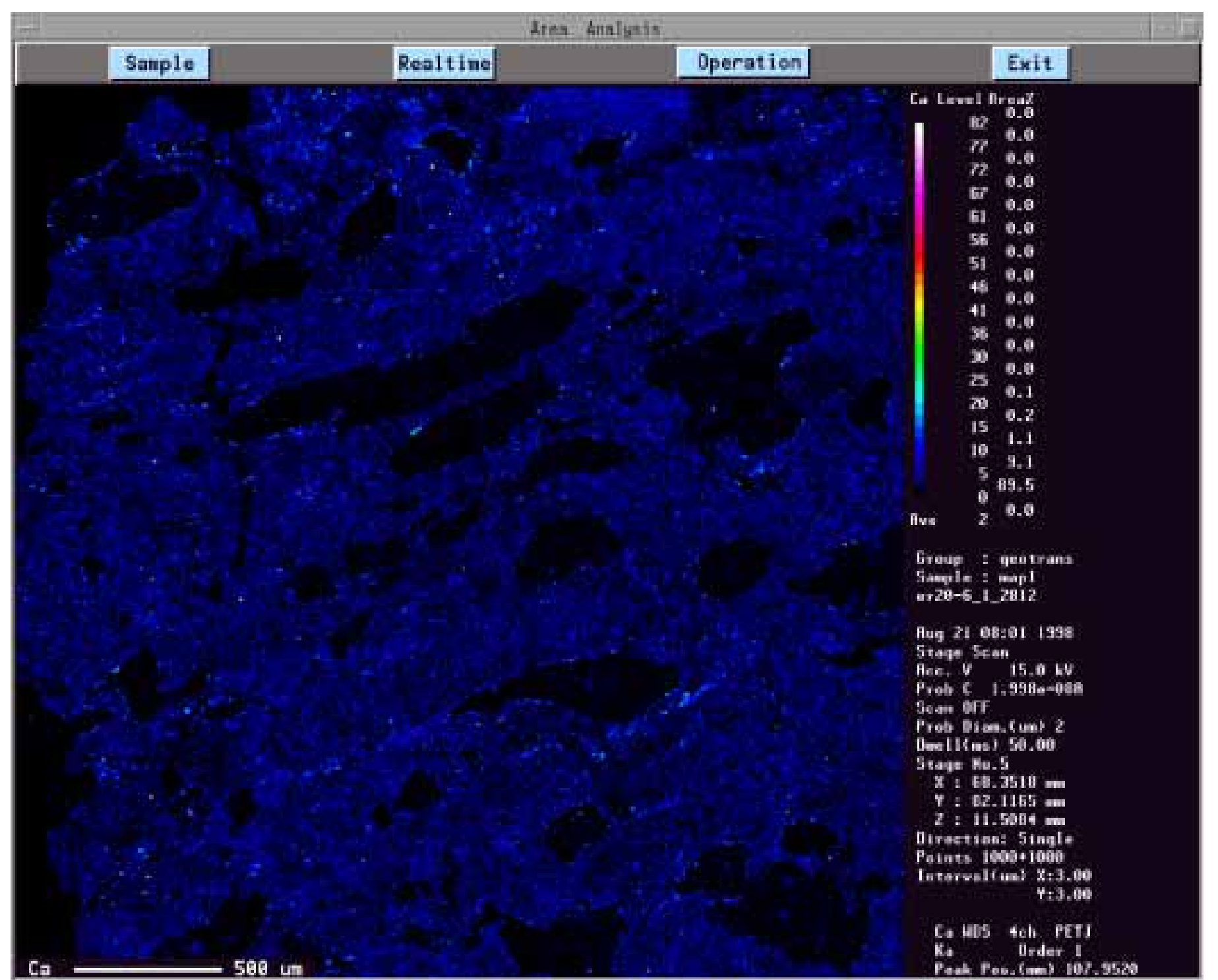

Figure 4-18

Elemental Map for Calcium $(2,812$ foot depth) 


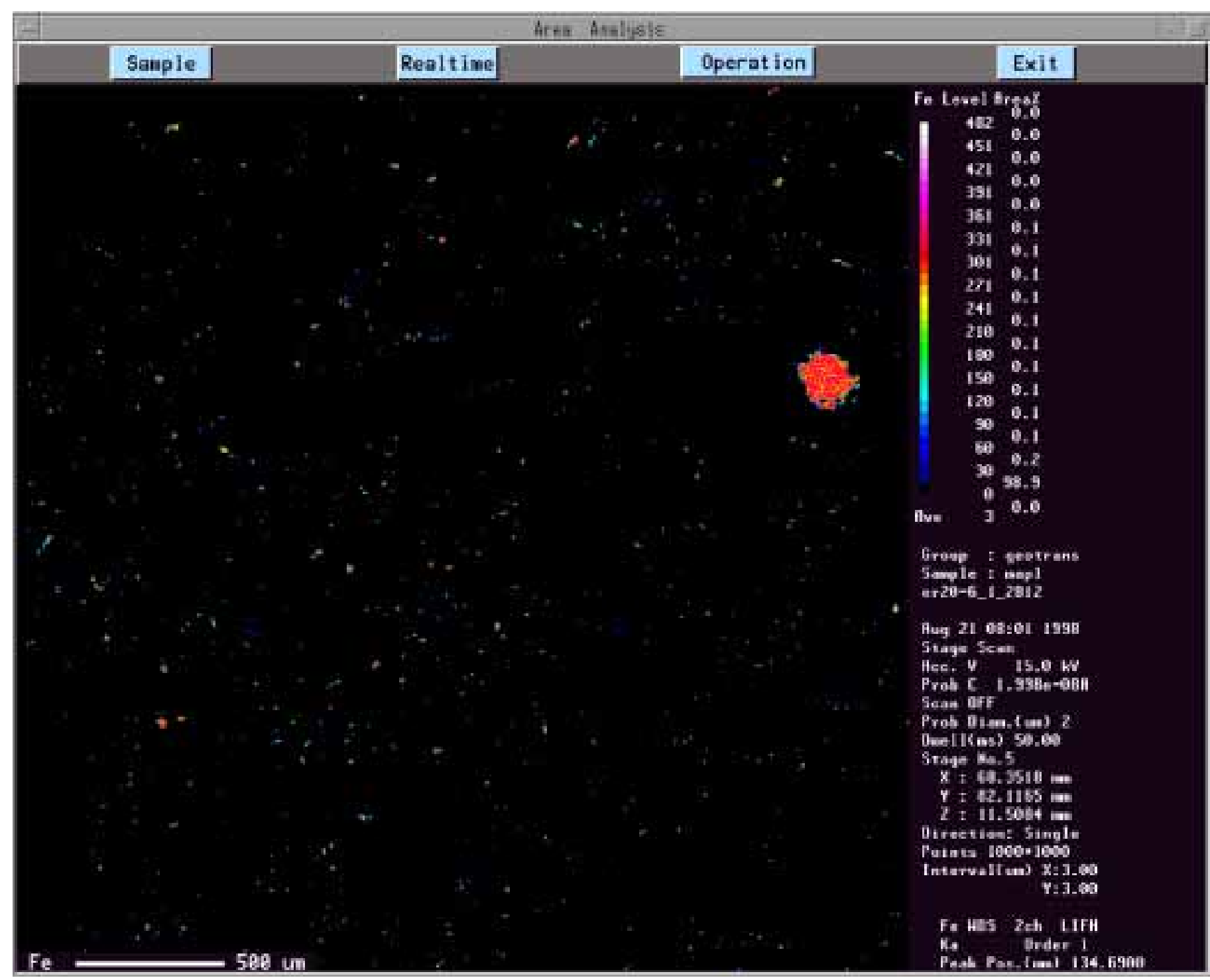

Figure 4-19 


\subsubsection{Optical Petrography}

Petrographic examination indicates that this sample is very similar overall to sample $2812 \mathrm{~B}$, described in the previous section. As noted here however, sample 2835B is lacking any evidence of fracture development. The visible color band in question is a textural and compositional segregation parallel to the predominant flow fabric. This band is composed of quartz and potassium feldspar crystals that are of a coarser grain size than the typical rock matrix. Similar to that seen in sample 2812B, the groundmass in sample 2835B consists of a flow banded matrix (0.025 to 0.05 millimeter) of quartz, potassium feldspar, biotite, and opaque minerals with phenocrysts of quartz (up to 0.75 millimeter), potassium feldspar (up to $0.25 \times 0.75$ millimeter), and plagioclase (up to $1.25 \times 1.25$ millimeter). Within the visible color band, typical grain size increases to 0.2 to 0.7 millimeter and is comprised almost exclusively of subhedral cracked or fractured quartz and subhedral to ragged alkali feldspar. The band matrix is comprised of clay (illite?).

\subsubsection{Scanning Electron Microscopy}

Due to the absence of any discernible natural fracture surfaces, this sample was not evaluated with the SEM.

\subsubsection{Electron Microprobe}

A thin section transecting the quartz/feldspar band shows it to be fairly subtle in the backscatter image (Figure 4-20-R) which reveals the textural relationships within the field of view. The microprobe analysis of this thin section also provided five elemental maps (one each for $K$, $\mathrm{Si}, \mathrm{Fe}, \mathrm{Na}$, and $\mathrm{Ca}$; Figures 4-20-L, 4-21-L, 4-21-R, 4-22-L, and 4-22-R, respectively) for the same area shown in the backscatter image. In order that such a large areal feature could be studied, the resolution in this set of images is not as fine as that in the microprobe images for the other samples. The number of pixels is limited by the instrumentation software to 1,000 pixels per axis. In order to evaluate the compositional band the pixel size for sample 2835B is 20 microns. For the other samples described in this report, smaller areas were evaluated and pixel size was either 2 or 3 microns. Several quantitative point analyses of discrete phases present in the thin section were performed and are summarized in Table 4-1.

As shown in Figure 4-20-R, the backscatter image shows the quartz/feldspar band transecting the image at an approximately 45 degree angle originating in the lower left hand corner and trending upward to the right. The backscatter image shows the subtle difference in average grain size between the matrix and the quartz/feldspar band. 


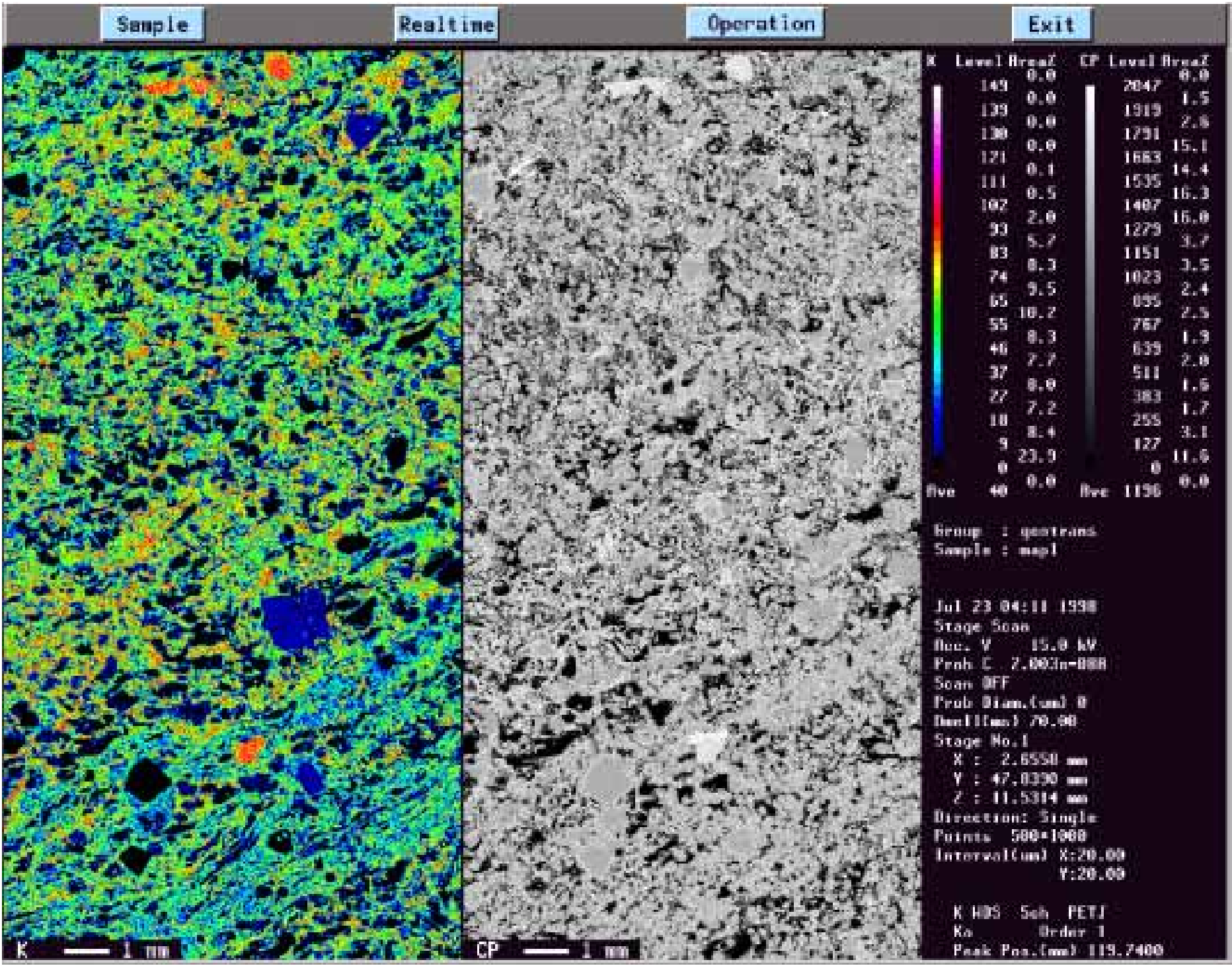

Figure 4-20

Elemental Map for Potassium (left) and Backscatter Image (right) (2,835 foot depth) 


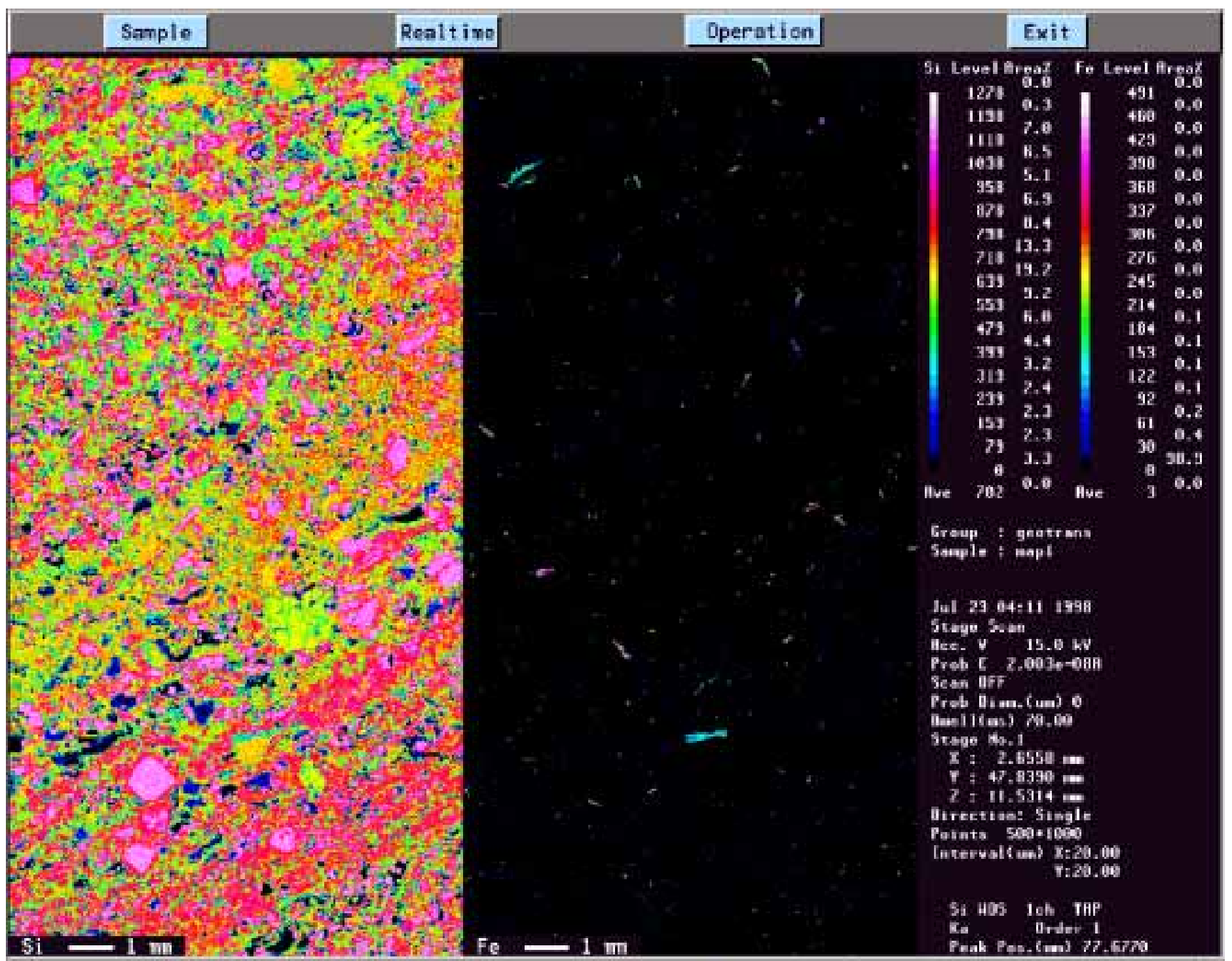

Figure 4-21

Elemental Map for Silica (left) and Iron (right) $(2,835$ foot depth) 

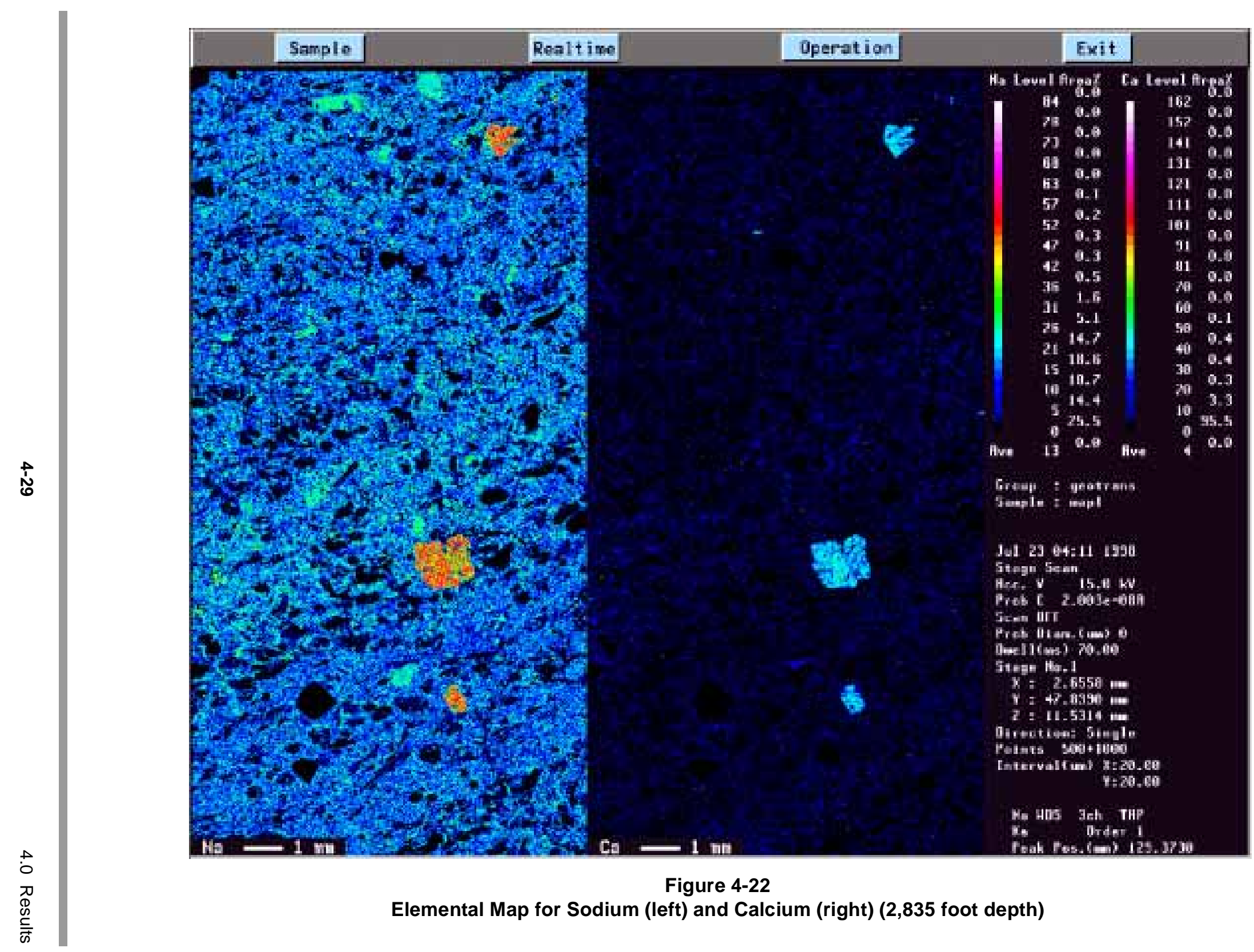

Figure 4-22

Elemental Map for Sodium (left) and Calcium (right) $(2,835$ foot depth) 
The elemental maps show the gross distribution of mineral phases in the sample. The potassium map (F igure 4-20-L) shows a low potassium zone (shown in blue to bluish-green) coincident with the color band. High concentration areas in the potassium map (shown in orange to red) are indicative of feldspars. The silica map (Figure 4-21-L ) shows a high concentration zone coincident with the low potassium zone, typified by quartz phenocrysts (light pink) with alkali feldspar overgrowths (purplish red). The other el emental maps add little information to the nature of the quartz/feldspar band. The iron map (F igure 4-21-R) reflects the presence of minor biotite and iron oxyhydroxides. The sodium map (Figure 4-22-L) and the calcium map (F igure 4-22-R) indicate the presence of sparse plagi oclase phenocrysts.

Four electron microprobe quantitative point analyses are included in Table 4-1. Two separate analyses of the rims on quartz crystals within the quartz/fel dspar band indicate the rims to be comprised of alkali feldspar. An analysis of the iron oxyhydroxide indicate that it contains minor amounts of $\mathrm{Mn}, \mathrm{Al}$, and $\mathrm{Ti}$ and al so contains approximately 7 percent by weight water. An analysis was also made of the large corroded plagioclase phenocryst within the quartz/feldspar band.

\subsection{Sample 2851.5B}

Existing information (Prothro et al, 1997) describes this material as a devitrified flow breccia from the lava flow aquifer of the Calico Hills Formation. Fracture density is indicated to be 2 to 3 fractures per foot of core. Texturally, the sample has been described (Prothro et al, 1997) as "clast-supported", with conspicuous vesicles to $5 \mathrm{~cm}$ aligned al ong fractures and flow banding. Mineralogically the sample contains rare phenocrysts of feldspar and quartz and rare biotite. This particular sample is lacking visible vesicles, but does have numerous open fractures (with apertures up to 5 millimeter) contained both within the sample and exposed on its surfaces. The properties of these fractures, and specifically any secondary mineral assemblage(s) formed on the fracture surfaces, are the focus of this activity.

\subsubsection{Optical Petrography}

Flow breccia texture is not evident on thin section scale. The sample is comprised of quartz (up to 0.5 millimeter) and potassium feldspar (up to 0.75 millimeter) phenocrysts in a finer grained ( 0.05 to 0.10 millimeter) matrix of predominantly quartz and feldspar.

In addition to the fracture face exposed on the sample exterior, several other fractures are present. Based on this limited sampling, there appear to be 2 general styles of fractures present. One set of fractures can be characterized as thin (0.01 millimeter), irregular, and 
discontinuous. The other set is typified by better devel oped, relatively wide (>0.25 millimeter), open, branching and through going fractures.

\subsubsection{Scanning Electron Microscopy}

SEM analysis of the exposed fracture surface (Figure 4-23), reveals abundant quartz crystals with irregular orientations and local clay mineral growths. As shown in Figure 4-24, clay minerals are present as mixed illite/smectite mats that cover entire portions of the exposed fracture surface. IIlite is also present after feldspar crystalites in the sample groundmass (Figure 4-25). Mixed illite/smectite is also present as web-like growths where voids are present between groundmass crystals as seen in Figure 4-26. The mixed illite/smectite covers approximately 51 percent of the of the fracture surface. Primary quartz and potassium feldspar comprise 26 percent and 23 percent respectively, of the fracture surface.

\subsubsection{Electron Microprobe}

A thin section transecting the exposed fracture surface al so contains a discontinuous subparallel fracture as shown in the backscatter image (F igure 4-27), which reveals the textural and structural relationships within the field of view. The microprobe analysis of this thin section also provided five elemental maps (one each for $\mathrm{Si}, \mathrm{Al}, \mathrm{K}, \mathrm{Ca}$, and $\mathrm{Fe}$; Figures 4-28, 4-29, 4-30, 4-31, and 4-32, respectively) for the same area shown in the backscatter image. In addition, several quantitative point analyses of discrete phases present in the thin section were performed and are summarized in Table 4-1.

As shown in Figure 4-27, the backscatter image shows the prominent open fracture surface as a near vertical feature along the right hand margin of the field of view. An additional parallel fracture is open and well devel oped in this sample as shown at the bottom of the image. Loses definition near the center of the image, where another diffuse, discontinuous fracture is present. The presence of small voids or gas cavities are indicated in the backscatter image and appear to be most abundant in the areas of the sample where alkali feldspar plus glass are localized. The backscatter image indicates that this sample has a relatively massive matrix and shows only subtle textural features at this scale.

The elemental maps show the gross distribution of mineral phases in the sample. The silica map (Figure 4-28), shows the quartz phenocrysts (indicated by the purplish pink color) and vol canic glass in the groundmass (indicated by the red to reddish orange color). The clay mat development along fracture surfaces is indicated on the silica map by the thin blue to bluish- green selvage. This selvage is also present 


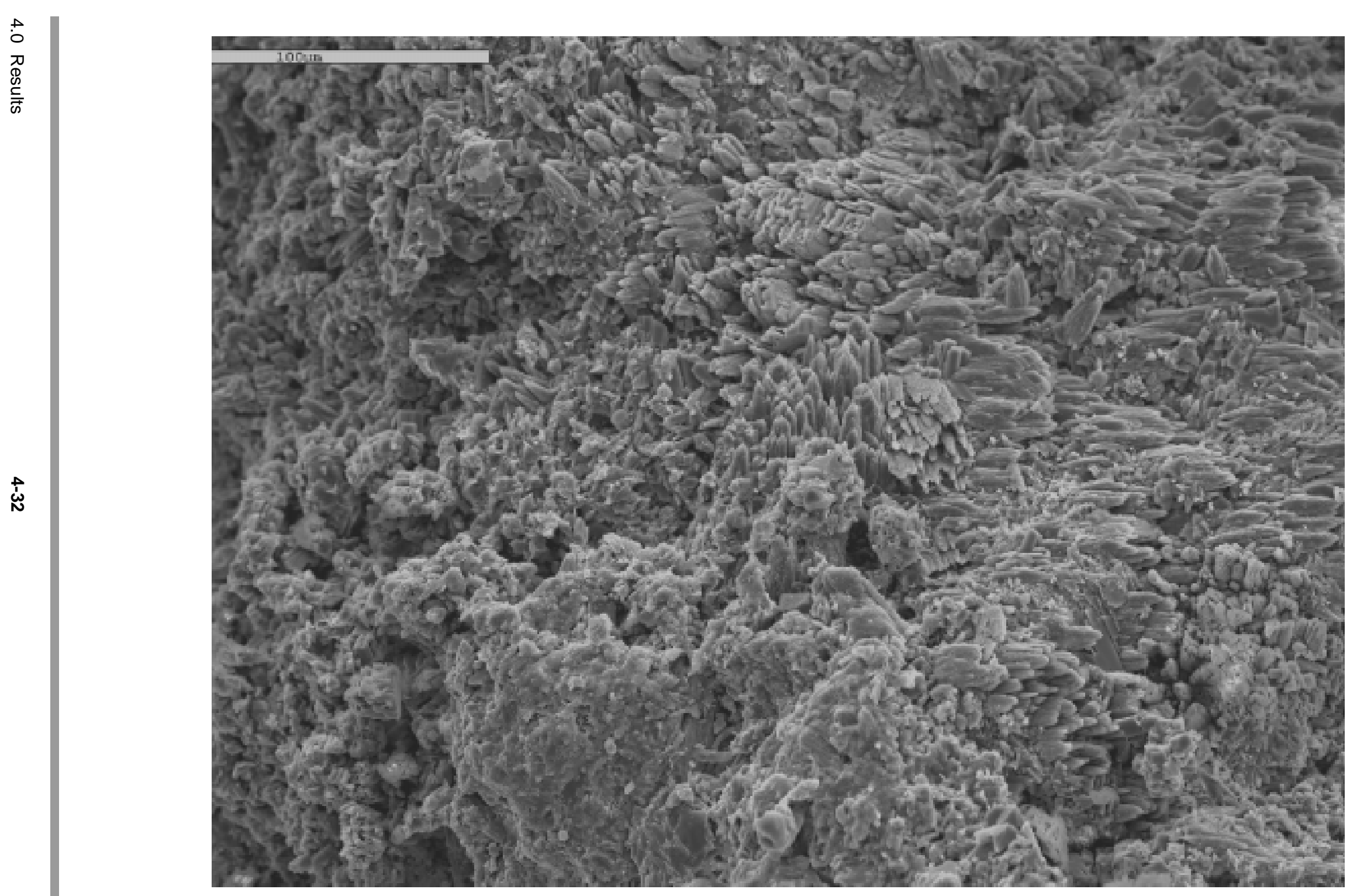

Figure 4-23

Overview of Fracture Surface (2,851.5 foot depth) 


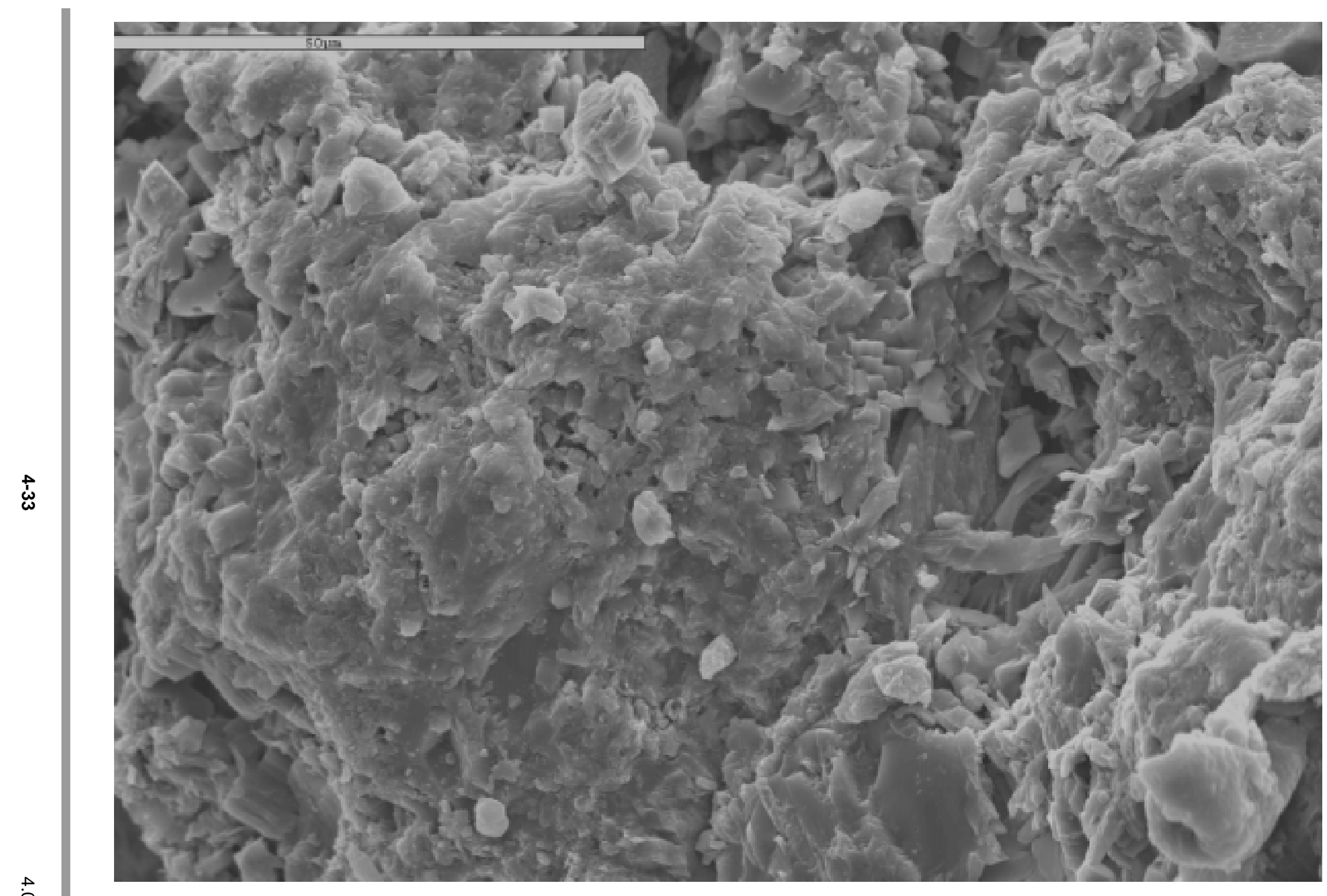

Figure 4-24 


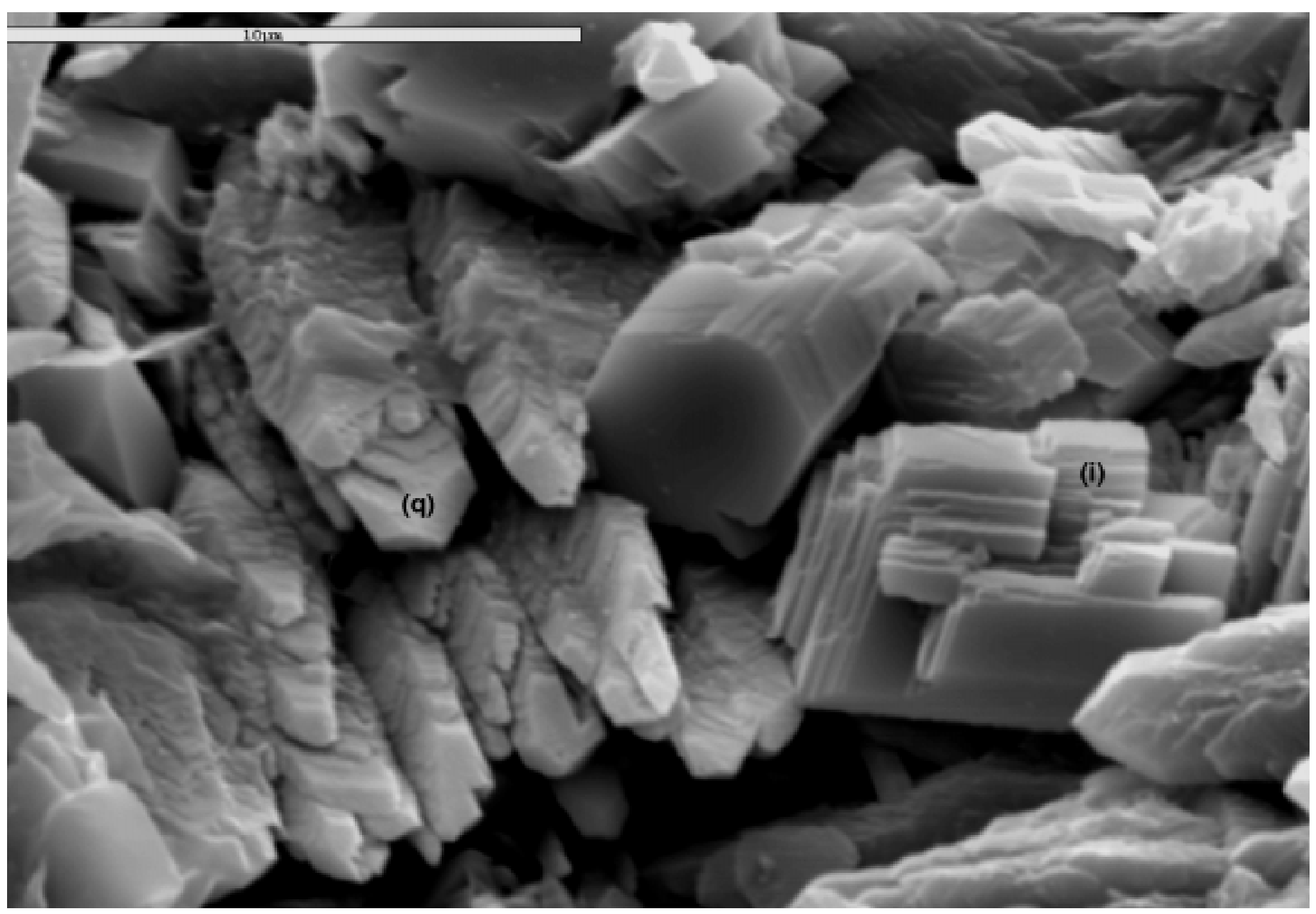

Figure 4-25

Quartz (q), with Illite after Feldspar (i), and Mixed Illite/Smectite (i/s) Clay (2,851.5 foot depth) 

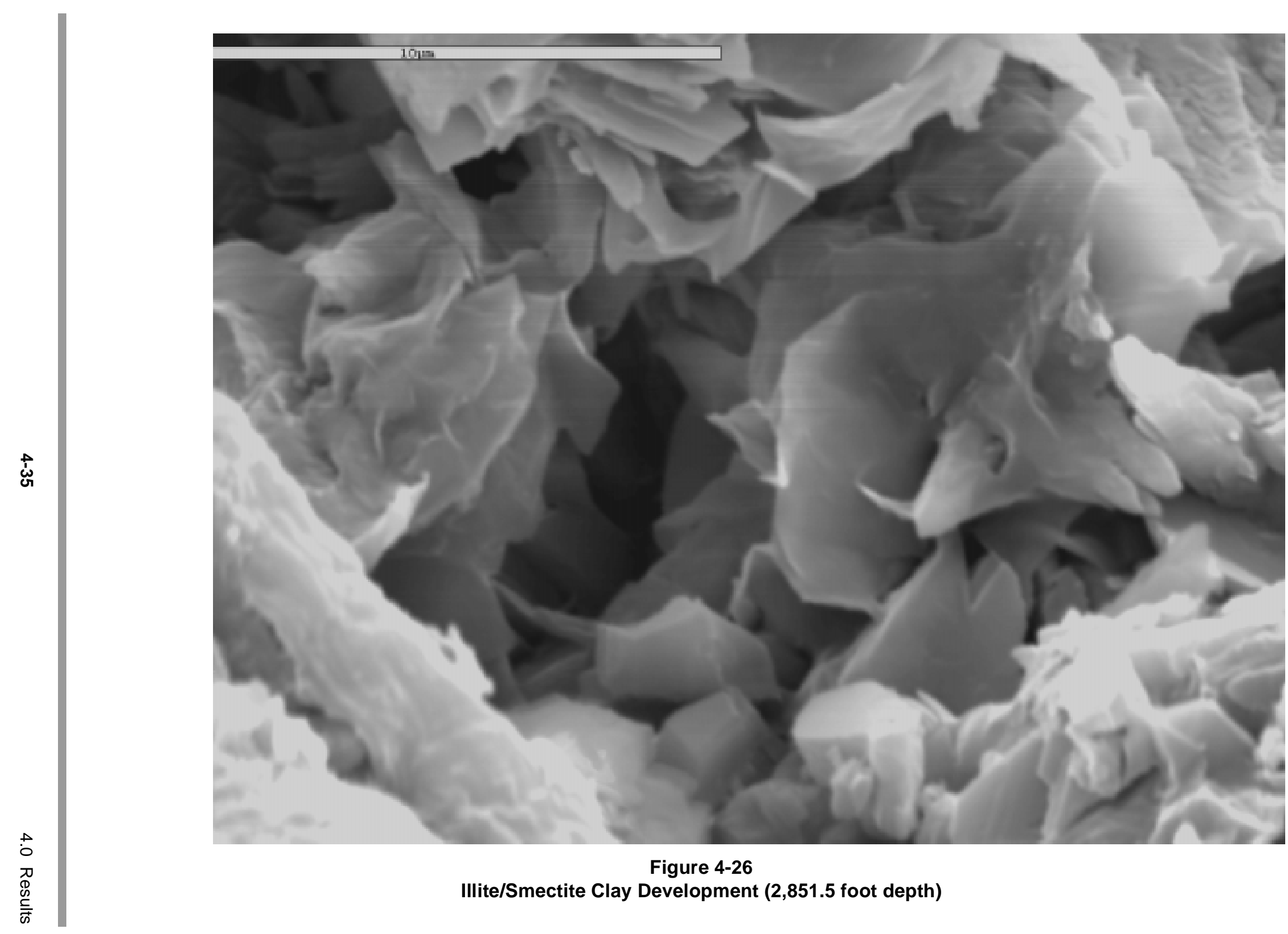

Figure 4-26

Illite/Smectite Clay Development (2,851.5 foot depth)

管 


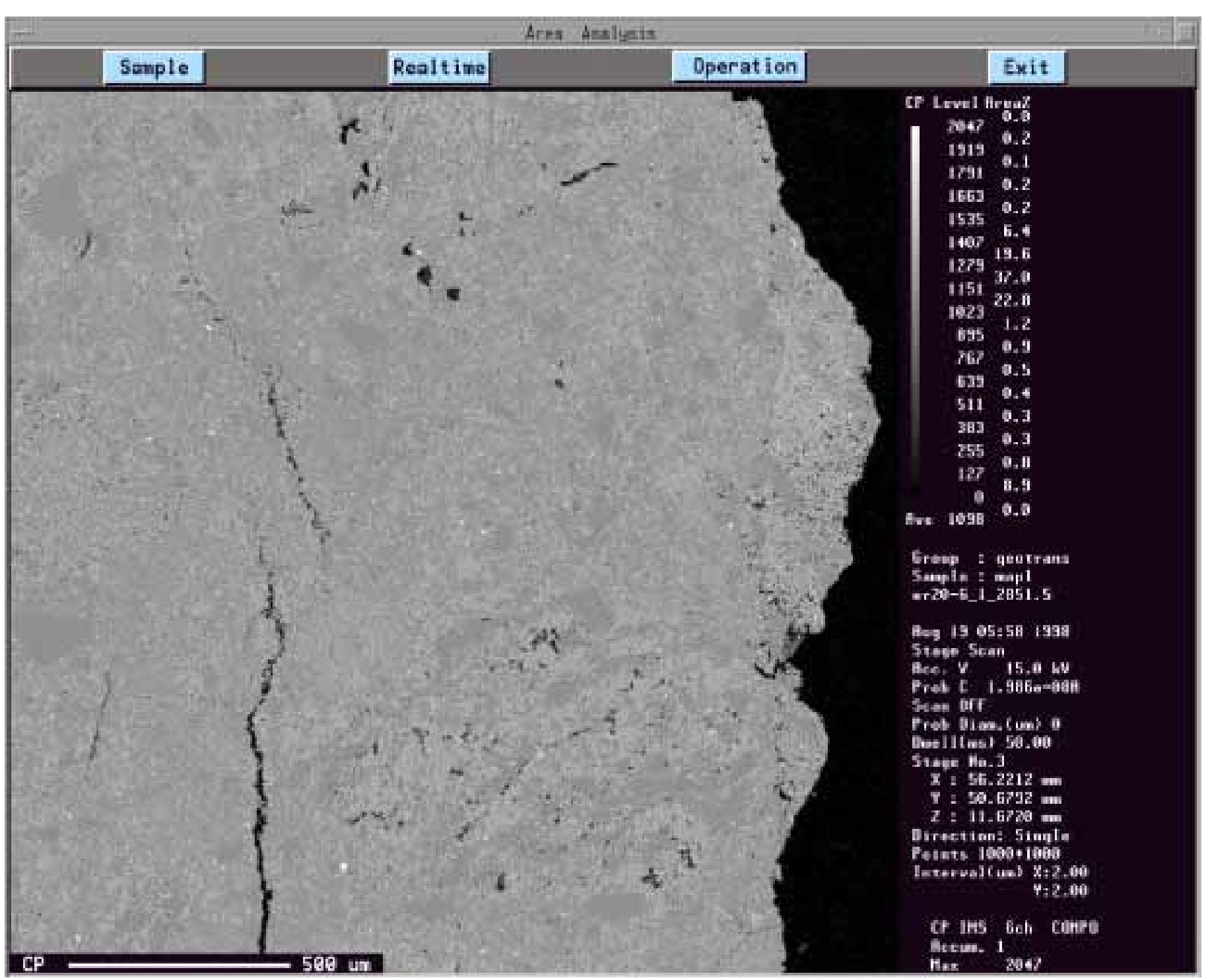

Figure 4-27

Backscatter Image (2,851.5 foot depth) 


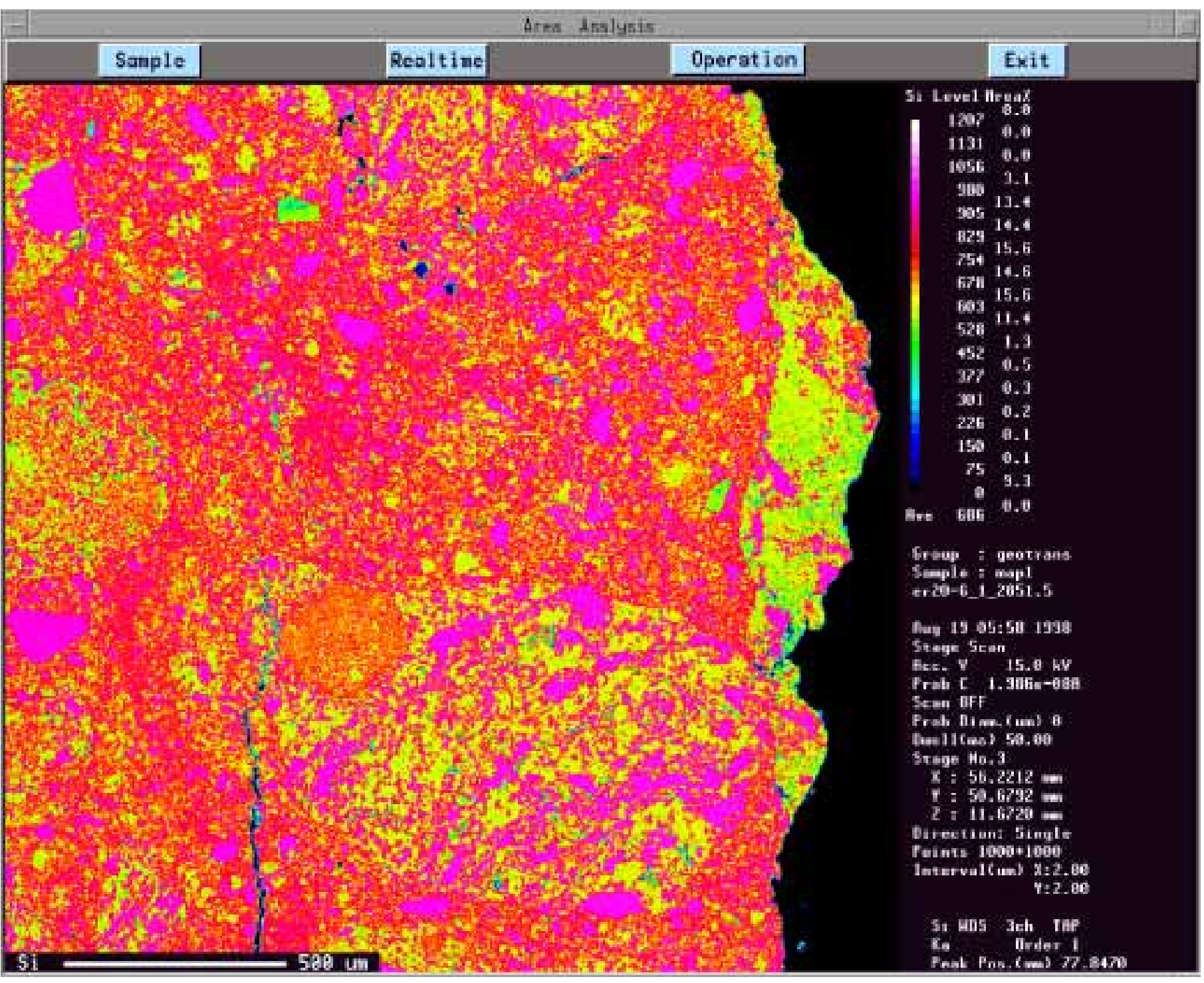

Figure 4-28 
lining what are assumed to be small gas cavities present particularly near the top center of the image. Alkali feldspar is present on the silica map in yellow. The aluminum map (Figure 4-29) also indicates the feldspars (in light blue) and reinforces the locations of the previously identified fractures. The potassium map (Figure 4-30), shows a greater range in concentration level than the aluminum map and clearly identifies the areas rich in alkali feldspar as well as the fractures visible in the silica map. Calcium (Figure 4-31), is of very low abundance in this sample, but two plagioclase feldspar phenocrysts (light blue phenocrysts near the top of the image) were identified. Similarly iron (Figure 4-32) is of generally low overall abundance in this sample, however, a relatively large (approximately 150 to 200 microns) iron-oxide phase (in red) is present near the upper right hand corner of the sample and is also present as much finer grains disseminated throughout the sample. 

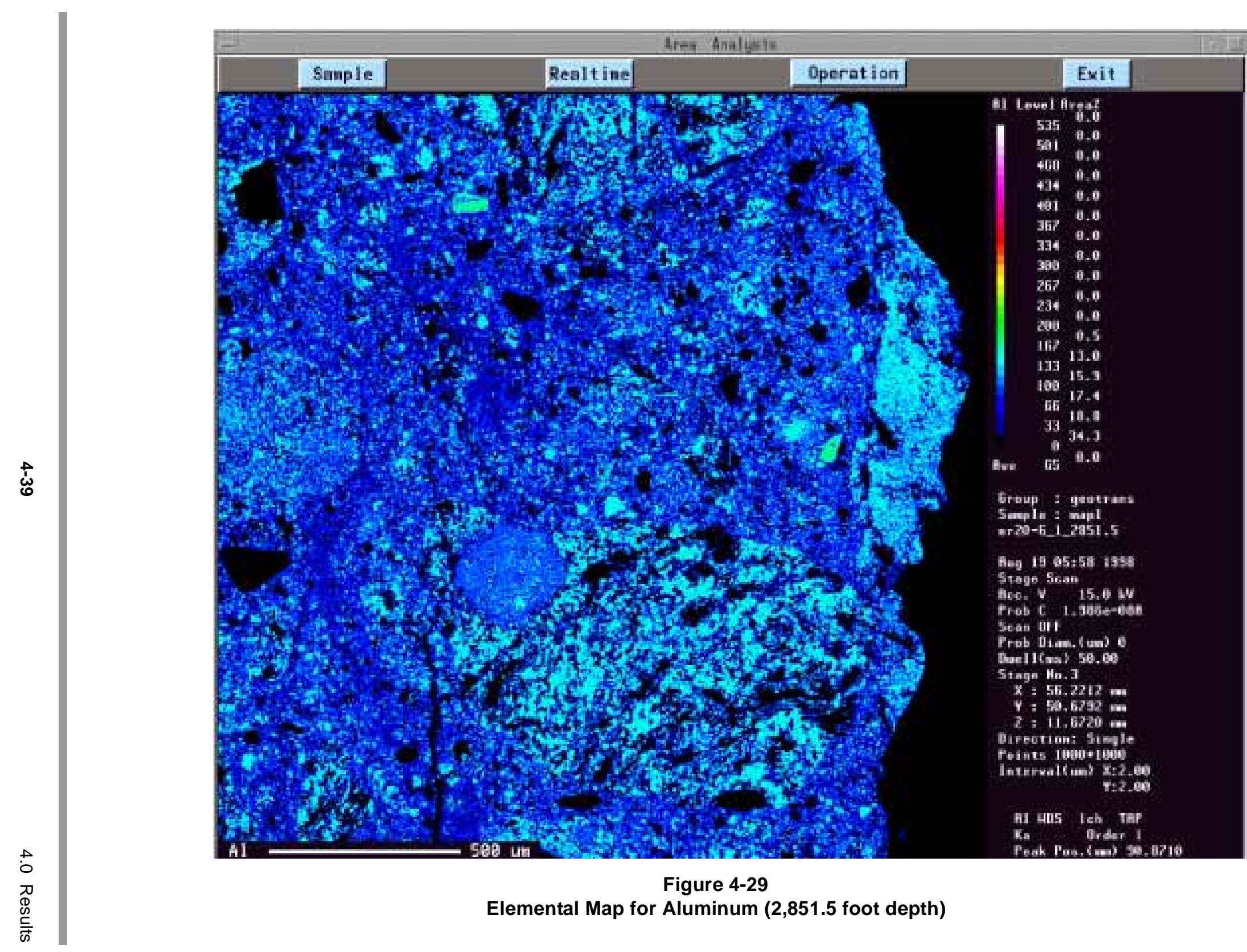

Figure 4-29

Elemental Map for Aluminum (2,851.5 foot depth) 


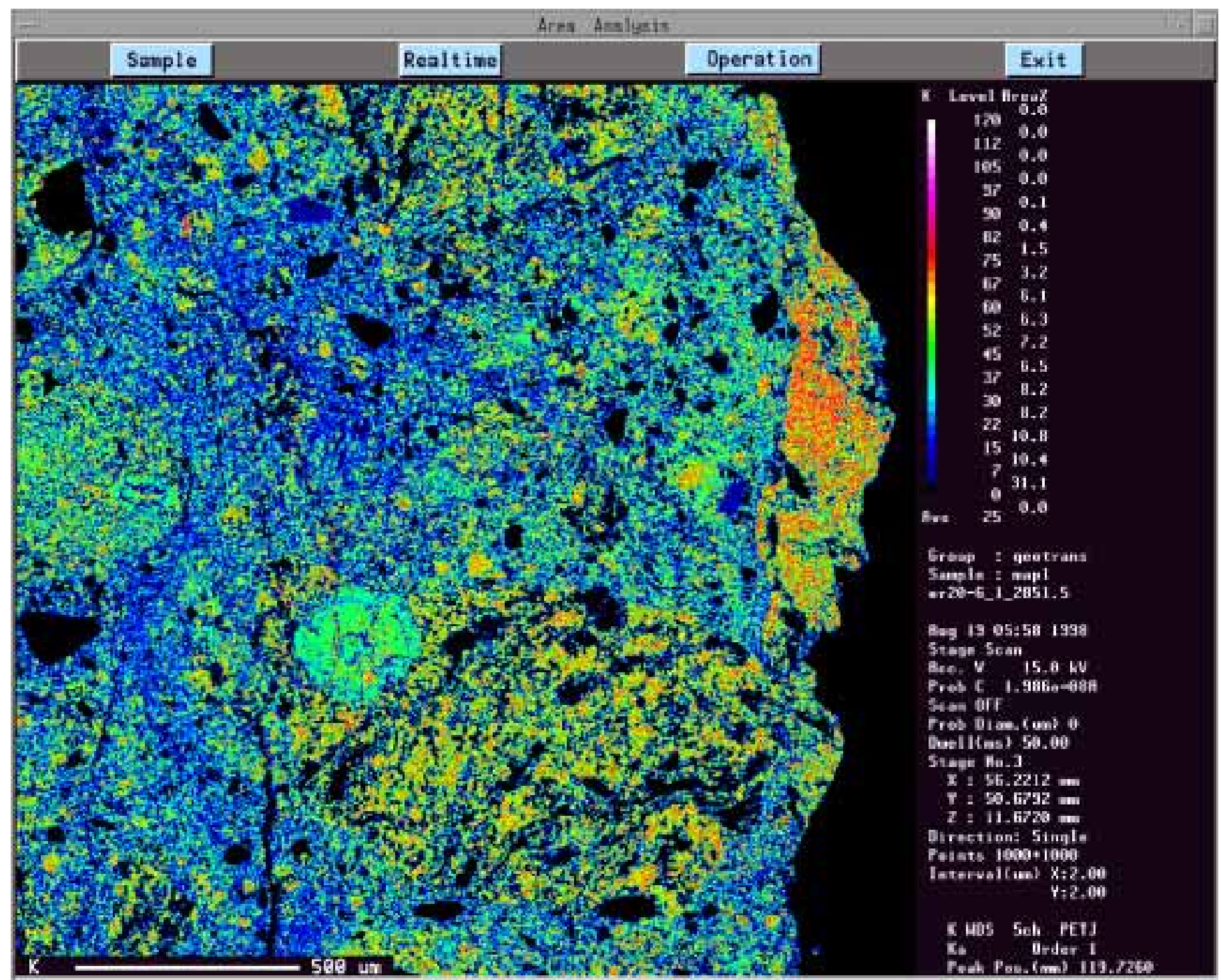

Figure 4-30

Elemental Map for Potassium (2,851.5 foot depth) 

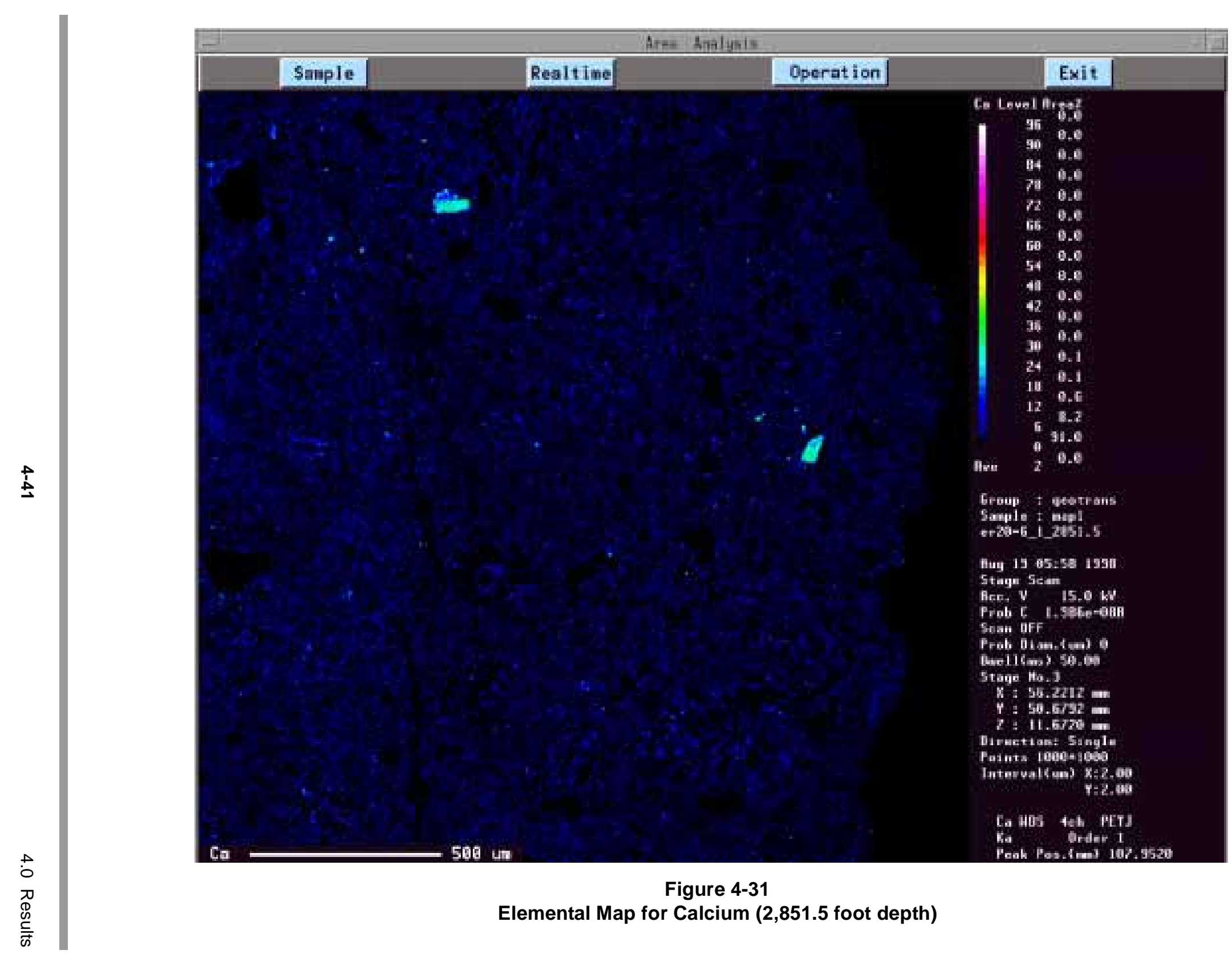

Figure 4-31

Elemental Map for Calcium (2,851.5 foot depth) 


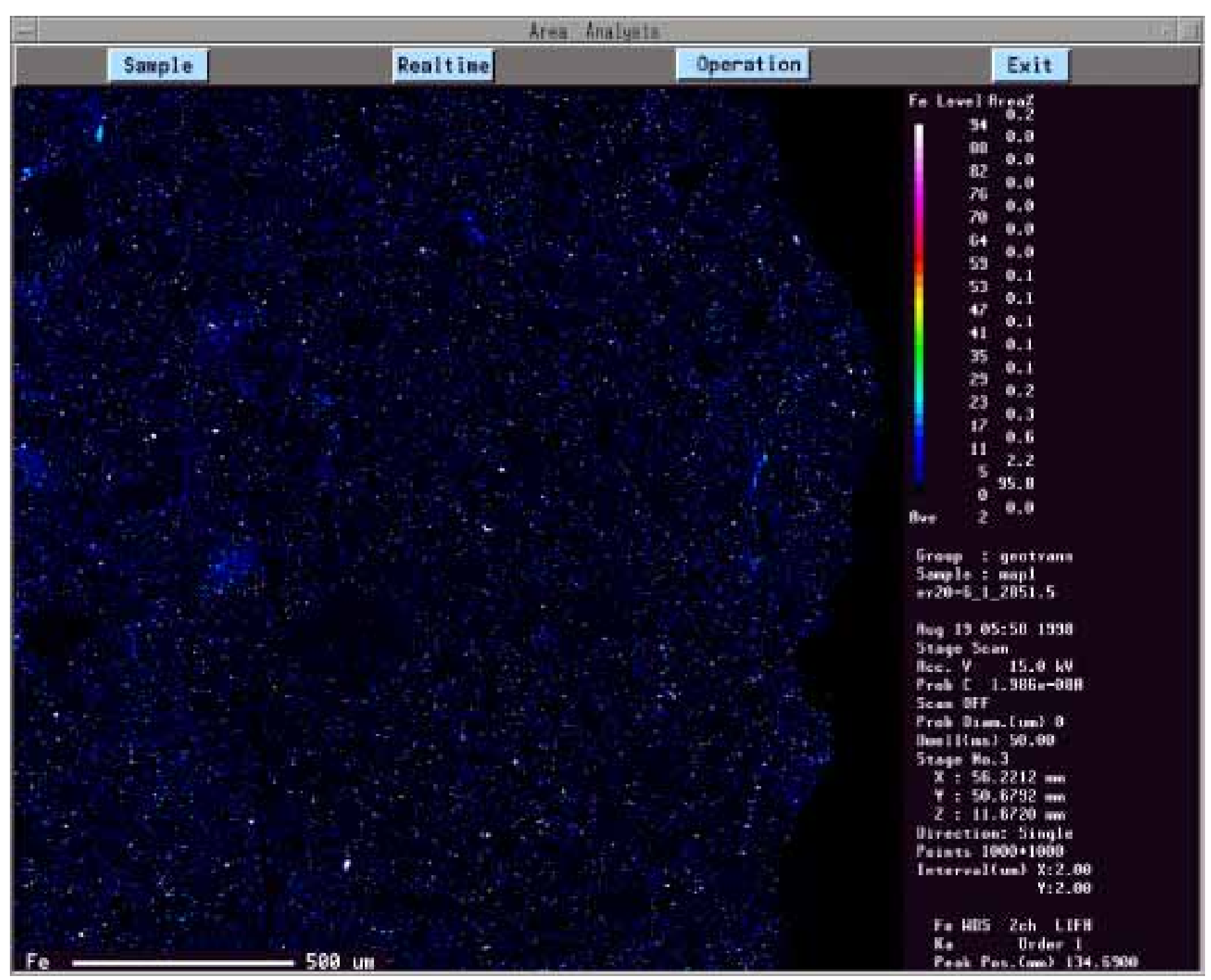

Figure 4-32

Elemental Map for Iron (2,851.5 foot depth) 


\subsection{Conclusions}

The core samples evaluated from E R-20-6\#1 are distinct from each other in terms of the style of microstructure devel opment. The samples are relatively similar to one another with regard to the secondary mineral assemblage development al ong the fractures that are present. All of the samples represented here are compositionally similar in terms of bulk chemistry, being part of the mafic-poor Calico Hills Formation (Prothro et al, 1997). This Formation has been recommended to be upgraded to the Calico Hills Group (Warren et al, 1998). Hydrostratigraphically, all of the samples evaluated are part of the Calico Hills Zeolitized Composite Unit (Prothro and Drellack, 1997). Sample 2236B comes from the non-welded tuff confining unit, samples 2812B and 2835B come from the devitrified lava of the lava-flow aquifer, and sample 2851.5B comes from the devitrified flow-breccia of the lava-flow aquifer.

There appear to be two distinct sets of fractures in sample 2236B. A set of discontinuous and irregular natural fractures are present in the sample which are typically largely blocked by an accumulation of mixed smectite/illite clay with opaline silica and a zeol ite phase tentatively identified as mordenite. There are also additional fractures which intersect these natural fractures at a high angle and appear to lack any secondary phase devel opment. These fractures are interpreted to be test induced as a result of proximity to the BULLION working point. The induced fractures appear to be open and are smaller in aperture than the natural fractures. There is not enough information contained in the small sample studied to speculate on the lateral continuity of the induced fractures.

Fracture development in sample 2812B is more uniform and regular (than those seen in sample 2236B) reflecting the increased competency of the devitrified lava. The fracture coating phase assemblage is also dominated by mixed smectite/illite clay, with illite after feldspar, and opaline silica. The fractures in this sample are only locally obstructed by secondary phase development.

A second sample collected from the devitrified lava interval (sample 2835B) was studied in order to characterize a linear band that is distinct in color from the bulk of the sample. The intent was to determine if this col or band was a secondary vein or fracture feature, or a primary flow band that developed at the same time as rock formation. The composition and texture of this band indicates it to be a 
concentrated band of quartz and feldspar that is coarser grained than the surrounding rock matrix. This band exhibits no particular compositional or structural properties that suggest it will have an influence on matrix diffusion any different than the bulk rock matrix. There were no secondary fractures observed in this sample.

Sample 2851.5B exhibits well developed open fractures with only thin coatings of secondary minerals. This reflects the competency and resistance to weathering of the flow breccia. I ntersecting fractures are widespread and well developed in this sample. Secondary mineral coatings of mixed illite/smectite clay and illite after feldspar are widespread but only thinly developed on the fracture surface. 


\subsection{References}

Gottardi, G., and E. Galli. 1985. Natural Zeolites. Berlin, Germany: Springer-Verlag, Berlin. 409 pp.

Prothro, L.B., and S.L. Drellack, J r. 1997. Nature and Extent of Lava-F low Aquifers Beneath Pahute Mesa, Nevada Test Site. DOE/NV/11718-156. Las Vegas, NV: Bechtel Nevada.

Prothro, L.B., M.J . Townsend, S.L. Drellack, J r., and J .L. Gonzales. 1997. Processing and Geological Analysis of Conventional Cores from Well ER-20-6\#1, Nevada Test Site, DOE/NV/11718-162, UC-703. Las Vegas, NV: Bechtel Nevada.

Warren., R.G., D.A. Sawyer, F.M. Byers, J r., and G.L. Cole. 1998. In preparation. A Petrographic/ Geochemical Database and Structural Framework for the Southwestern Nevada Volcanic Field. Los Alamos, NM: Los Alamos National Laboratory Report. 


\section{Distribution}

\section{$\underline{\text { Copies }}$}

Paul Reimus

CST-7 Chemical Science and Technology

MSJ 534

Los Alamos National Laboratory

Los Alamos, NM 87545

Rick Warren

Los Alamos National Laboratory

MSD462

Los Alamos, NM 87545

Rick Waddell

HSI Geotrans

9101 Harlan, Suite 210

Westminster, CO 80030

Chris Benedict

HSI Geotrans

50 W Liberty St., Suite 580

Reno, NV 81501

Robert Bangerter

DOE/Nevada Operations Office

Environmental Restoration Division

P.O. Box 98518, M/S 505

Las Vegas, NV 89193-8518

Robert Sobocinski

IT Corporation

2621 Losee Road, BIdg. B-1

M/S 439

North Las Vegas, NV 89030

J anet Wille

IT Corporation

2621 Losee Road, BIdg. B-1

M/S 439

North Las Vegas, NV 89030

Central Files

IT Corporation

2621 Losee Road, BIdg. B-1

M/S 439

North Las Vegas, NV 89030 